\title{
Imaging findings of mucopolysaccharidoses: a pictorial review
}

\author{
Stefano Palmucci • Giancarlo Attinà • Maria Letizia Lanza • Giuseppe Belfiore • \\ Giuseppina Cappello • Pietro Valerio Foti • Pietro Milone • Domenico Di Bella • \\ Rita Barone • Agata Fiumara • Giovanni Sorge • Giovanni Carlo Ettorre
}

Received: 22 December 2012 /Revised: 18 March 2013 / Accepted: 25 March 2013 /Published online: 5 May 2013

(C) The Author(s) 2013. This article is published with open access at Springerlink.com

\begin{abstract}
Introduction Mucopolysaccharidosis (MPS) represent a heterogeneous group of inheritable lysosomal storage diseases in which the accumulation of undegraded glycosaminoglycans (GAGs) leads to progressive damage of affected tissues. The typical symptoms include organomegaly, dysostosis multiplex, mental retardation and developmental delay. Definitive diagnosis is usually possible through enzymatic assays of the defective enzyme in cultured fibroblasts or leukocytes.

Imaging findings Radiological and neuroradiological findings are reported. The most important neuroradiological features include abnormal signal intensity in the white matter, dilatation of periventricular spaces, widening of cortical sulci, brain atrophy, enlargement of extraventricular spaces and spinal cord compression. With reference to the skeletal system, most important radiological findings include multiplex dysostosis, which is represented by several bone
\end{abstract}

S. Palmucci $(\bowtie) \cdot$ G. Attinà $\cdot$ M. L. Lanza $\cdot$ G. Cappello $•$

P. V. Foti $\cdot$ P. Milone $\cdot$ G. C. Ettorre

Radiodiagnostic and Oncological Radiotherapy Unit,

University Hospital "Policlinico-Vittorio Emanuele",

Via Santa Sofia 78,

95123 Catania, Italy

e-mail: spalmucci@sirm.org

G. Belfiore $\cdot$ D. Di Bella

Unit of Pediatric Radiology, Hospital "Policlinico-Vittorio

Emanuele", Via Santa Sofia 78,

95123 Catania, Italy

R. Barone $\cdot$ A. Fiumara $\cdot$ G. Sorge

Department of Pediatrics, Regional Referral Centre for Inborn

Errors Metabolism, University Hospital "Policlinico-Vittorio

Emanuele", Via Santa Sofia 78,

95123 Catania, Italy malformations found in the skull, hands, legs, arms and column. The abnormal storage of GAGs leads to liver and spleen enlargement; it also damages cartilage layers and synovial recesses in the joints.

Conclusion The aim of this pictorial essay is to describe the imaging findings of MPS, represented by skeletal and neurological features; skeletal X-ray and MR allow an assessment of the severity of disease, to plan medical and surgical therapy and to evaluate response to treatment.

Teaching Points

- To describe the imaging findings common to different types of MPS.

- To describe multiplex dysostosis encountered in the axial and appendicular skeleton.

- To evaluate neuroradiological features of MPS, including brain abnormal signal intensity and atrophy.

- To evaluate important otorhinolaryngological problems, such as otitis media and airways obstruction.

Keywords Glycosaminoglycans - Metabolic diseases · Lysosomal storage diseases $\cdot$ Dysostoses $\cdot$ Magnetic resonance imaging

\section{Introduction}

The mucopolysaccharidoses (MPS) are a group of heritable lysosomal storage disorders caused by a deficiency in glycosaminoglycan (GAG)-degrading enzymes. The resulting accumulation of unprocessed or partly processed GAGs - dermatan sulphate, heparan sulphate, keratan sulphate and chondroitin sulphate - in lysosomes causes progressive damage of affected tissues, including heart, respiratory system, bones, joints and central nervous system [1]. Seven distinct clinical types of MPS have been identified and described in the literature, caused by 
11 different enzymatic deficiencies. Even if each type of MPS presents a rare incidence, the overall incidence is not negligible ( 1 in 25,000 live births). Transmission occurs in an autosomal recessive fashion, except for MPS II, which is X-linked [2].

The ubiquitous nature of GAGs within the connective tissue of the body results in a wide range of clinical effects. The type of GAGs stored and the classification of disease depend on the specific enzyme deficiency [3]. Table 1 outlines the latest classification, with details of the accumulating compounds and enzymes deficiencies, as well as the eponym used for each condition.

Like most genetic disorders, there is a continuous spectrum of phenotype from the very severe to the most mildly affected; many mutations are responsible for these phenotypic differences [2]. The typical symptoms, encountered in the majority of MPS, include organomegaly, dysostosis multiplex, mental retardation and developmental delay. Otological (otitis media) and respiratory (airway obstruction) problems can also be present. Other manifestations include impaired vision (corneal clouding and photophobia) [4] and cardiovascular involvement (myocardial hypertrophy, systolic dysfunction and valve dysfunction) [5-7].
The course of MPS is variable from very severe forms, with an average expected life span of 1 or 2 decades (neuronopathic forms in particular are usually fatal diseases) to attenuated or slowly progressing ones that allow the patient to reach adulthood $[1,3,8]$.

A combination of clinical picture and analysis of urinary GAGs is usually performed to achieve the diagnosis of MPS, even though this method cannot recognise subtypes; definitive diagnosis is usually possible through measuring enzyme activity in cultured fibroblasts or leukocytes [1,2].

Treatment consists mainly of symptomatic and supportive care, including decompression of the craniocervical narrowing, tracheostomy insertion and corneal transplantation. In recent years the development of new therapies-represented by enzyme replacement therapies, substrate inhibition therapy and haematopoietic cell transplantation - have changed the treatment of these patients, with a fundamental shift in the approach from symptomatic management to therapeutic intervention; in many cases, the introduction of these new therapies has significantly improved the duration and quality of life for patients $[9,10]$.

Table 1 Summary of epidemiological, pathophysiological and clinical features characterising different types of MPS

\begin{tabular}{|c|c|c|c|c|c|}
\hline Type & Name of syndrome & Incidence & Deficient enzyme & $\begin{array}{l}\text { Accumulated } \\
\text { products }\end{array}$ & Main symptoms \\
\hline \multirow[t]{3}{*}{ I } & \multirow[t]{2}{*}{ Hurler (I H) } & \multirow[t]{3}{*}{$1 / 100.000$} & \multirow[t]{3}{*}{ Alpha-L-iduronidase } & HS & $\begin{array}{l}\text { Corneal clouding; dysostosis multiplex; } \\
\text { organomegaly; heart disease; mental } \\
\text { retardation; death in childhood }\end{array}$ \\
\hline & & & & \multirow[t]{2}{*}{ DS } & $\begin{array}{l}\text { Corneal clouding; stiff joints; normal } \\
\text { intelligence and life span }\end{array}$ \\
\hline & $\begin{array}{l}\text { Scheie (I S) } \\
\text { Hurler-Scheie (I H-S) }\end{array}$ & & & & $\begin{array}{l}\text { Intermediate phenotype, between MPS } \\
\text { IH and MPS IS }\end{array}$ \\
\hline II & Hunter & $1 / 250.000$ & Iduronate sulphatase & $\begin{array}{l}\text { HS } \\
\text { DS }\end{array}$ & $\begin{array}{l}\text { Dysostosis multiplex; organomegaly; } \\
\text { short stature; death before } 15 \text { years } \\
\text { (severe);survival to } 20 \text { s to } 60 \text { s (mild) }\end{array}$ \\
\hline \multirow[t]{3}{*}{ III } & $\begin{array}{l}\text { Sanfilippo A } \\
\text { Sanfilippo B }\end{array}$ & \multirow[t]{3}{*}{$1 / 150.000$} & $\begin{array}{l}\text { Heparan sulphamidase } \\
\text { N-acetyl-glucosaminidase }\end{array}$ & \multirow[t]{3}{*}{ HS } & \multirow{3}{*}{$\begin{array}{l}\text { Relatively mild somaticmanifestations; } \\
\text { hyperactivity; profound mental } \\
\text { deterioration }\end{array}$} \\
\hline & Sanfilippo C & & $\begin{array}{l}\text { Acetyl-CoA: alpha-glucusaminide } \\
\text { acetyltranferase }\end{array}$ & & \\
\hline & Sanfilippo D & & $\mathrm{N}$-acetylglucosamine 6-sulphatase & & \\
\hline \multirow[t]{2}{*}{ IV } & \multirow[t]{2}{*}{ Morquio B } & \multirow[t]{2}{*}{$1 / 75.000$} & Galactose-6-sulphate sulphatase & $\begin{array}{l}\mathrm{KS} \\
\mathrm{CH}\end{array}$ & \multirow[t]{2}{*}{$\begin{array}{l}\text { Dysostosis multiplex; short stature; } \\
\text { motor dysfunction }\end{array}$} \\
\hline & & & Beta-galactosidase & $\mathrm{KS}$ & \\
\hline $\mathrm{V}$ & \multicolumn{5}{|c|}{ This designation is no longer used; the phenotype, which was first classified as MPS V, was found to be MPS I S } \\
\hline VI & Maroteaux-Lamy & $<1 / 250.000$ & $\mathrm{~N}$-acetylgalactosamine-4-sulphatase & DS & $\begin{array}{l}\text { Dysostosis multiplex; short stature; } \\
\text { motor dysfunction; kyphosis; heart } \\
\text { defects; survival to teens in } \\
\text { severe form }\end{array}$ \\
\hline VII & Sly & $<1 / 250.000$ & Beta-glucuronidase & $\begin{array}{l}\mathrm{HS} \\
\mathrm{DS} \\
\mathrm{CH}\end{array}$ & $\begin{array}{l}\text { Hepatomegaly; dysostosis multiplex; } \\
\text { short stature; corneal clouding; } \\
\text { developmental delay; wide spectrum } \\
\text { of severity including fetal hydrops } \\
\text { and neonatal form }\end{array}$ \\
\hline
\end{tabular}




\section{Imaging findings}

In patients with MPS, radiological and neuroradiological imaging findings have been described [11]. The most important radiological findings occur in the skeletal system with multiplex dysostosis (Table 2), a complex of anomalies involving several bones [12-14], dominating the clinical picture in MPS IV and MPS VI.

Table 2 Radiological skeletal manifestations of MPS: dysostosis multiplex

Dysostosis multiplex

\begin{tabular}{|c|c|}
\hline \multirow[t]{8}{*}{ Skull } & Macrocephaly with dolicocephaly \\
\hline & Vertical frontal crest \\
\hline & Abnormal J-shaped sella turcica \\
\hline & Thickened cortical bone \\
\hline & Facial anomalies \\
\hline & $\begin{array}{l}\text { Lack of pneumatization of mastoid } \\
\text { process } \\
\text { cells and of paranasal cavities }\end{array}$ \\
\hline & $\begin{array}{l}\text { Obtuse mandibular angle with } \\
\text { prognatism }\end{array}$ \\
\hline & Teeth widely spaced \\
\hline \multirow[t]{2}{*}{ Thorax } & $\begin{array}{l}\text { Paddle-shaped or oar-shaped ribs } \\
\text { (widened } \\
\text { anteriorly and tapered posteriorly) }\end{array}$ \\
\hline & Short and thickened clavicles \\
\hline \multirow[t]{3}{*}{ Spine } & $\begin{array}{l}\text { Craniovertebral junction: atlantoaxial } \\
\text { instability, stenosis and compression } \\
\text { of the spinal cord }\end{array}$ \\
\hline & Thoracolumbar spine: gibbus \\
\hline & Malformations of the vertebral bodies \\
\hline \multirow[t]{6}{*}{ Pelvis } & Rounded iliac wings \\
\hline & Inferior tapering of the ileum \\
\hline & Hip dysplasia \\
\hline & Poorly developed acetabulum \\
\hline & $\begin{array}{l}\text { Underdevelopment of the medial } \\
\text { portion of the proximal femoral } \\
\text { epiphysis }\end{array}$ \\
\hline & Coxa valga \\
\hline \multirow[t]{3}{*}{ Long bones } & Mildly hypoplastic epiphyses \\
\hline & Proximal humeral notching \\
\hline & Long and narrow femoral neck \\
\hline Knees & Genu valgum \\
\hline \multirow[t]{4}{*}{ Hands and feet } & $\begin{array}{l}\text { V-shaped deformity of the } \\
\text { hypoplastic } \\
\text { distal ulna and radius }\end{array}$ \\
\hline & $\begin{array}{l}\text { Hypoplastic and irregularly shaped } \\
\text { carpal } \\
\text { and tarsal bones }\end{array}$ \\
\hline & $\begin{array}{l}\text { Proximal pointed metacarpals and } \\
\text { metatarsals }\end{array}$ \\
\hline & Bullet-shaped phalanges \\
\hline
\end{tabular}

The abnormal storage of GAG in the mouth, nose, pharynx and larynx results in several otorhinolaryngological disorders; in view of this, otorhinolaryngological imaging findings have been described. Patients can also show hepatomegaly and splenomegaly.

Regarding neuroradiological features, the involvement of the central nervous system is predominant in MPS I, II, III and MPS VII $[15,16]$.

In this pictorial review we focus on skeletal, otorhinolaryngological and neuroradiological imaging findings encountered in patients with MPS.
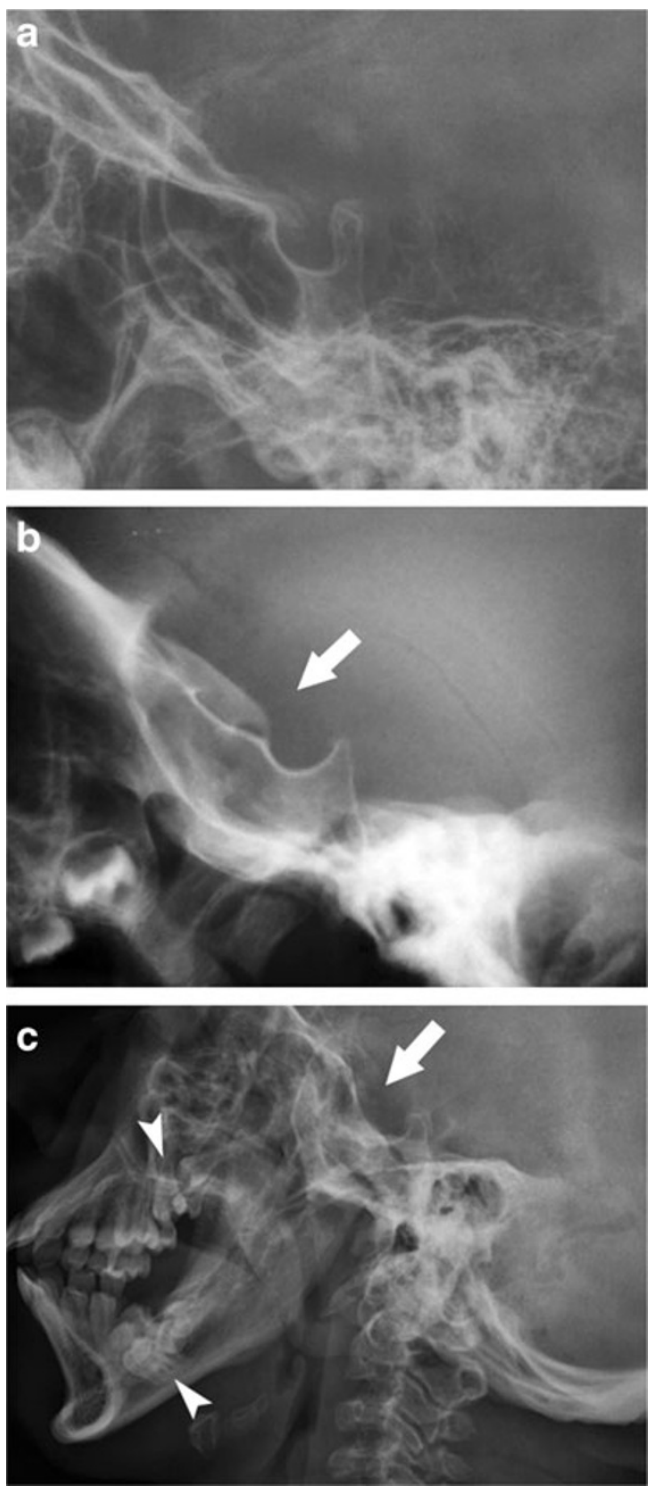

Fig. 1 Magnified views of lateral skull radiographs. Normal skull, presenting a regularly shaped sella (a). Skull of a 2-year-old patient affected by MPS VI (b); the abnormal J-shaped sella (white arrow), is clearly recognisable. Skull of a 17 -year-old patient affected by MPS VI (c), presenting a J-shaped sella (white arrow) and some molars unerupted and angulated in both the jaws (white arrowheads) 
Fig. 2 Thoracic abnormality. Frontal radiographs showing a normal chest in a 10 -year-old girl (a) and a chest of a 10-yearold girl affected by MPS IV (b), the latter presenting ribs (white arrowheads) tapered proximally and wider distally; broad and short clavicles (white arrow) can be seen in the magnified view of the clavicles (c)
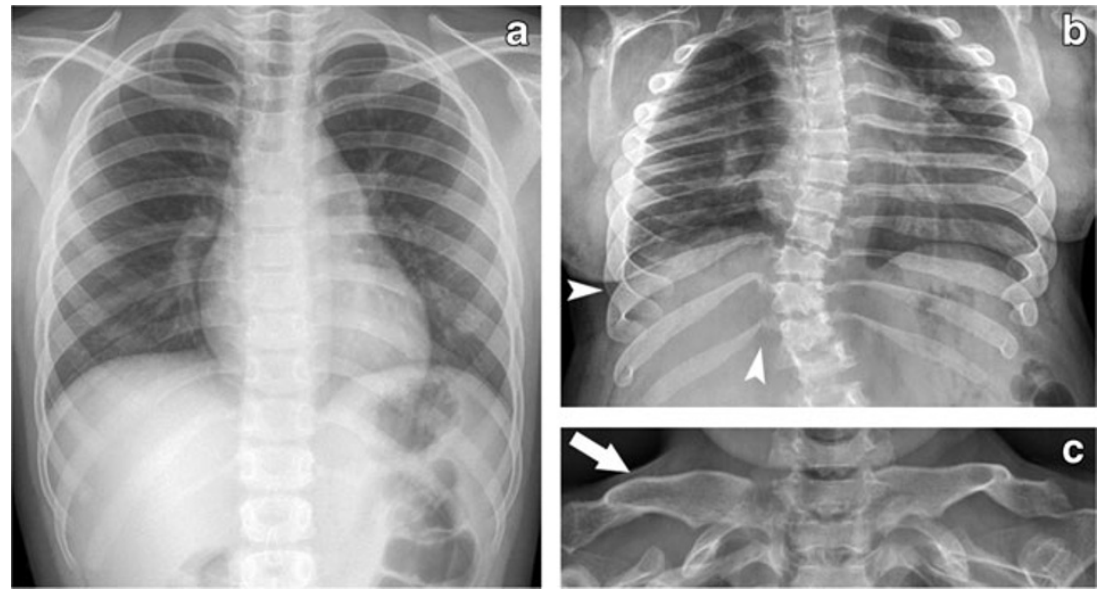

Skeletal imaging findings

\section{Axial skeleton}

The most important radiological findings in the axial skeleton regard the skull, thorax, spine and pelvis.

The skull is often characterised by an abnormal " $\mathrm{J}$ shaped" conformation of the sella turcica, seen on the lateral view of the cranium (Fig. 1). The sella turcica is normally a saddle-shaped depression in the sphenoid bone, while in MPS patients it is usually wide with long clinoid apophyses and horizontal orientation: the tuberculum sellae is flattened and the dorsum sellae is rounded, respectively, forming the straight edge and the loop of the "J". This configuration may represent a normal anatomic variant and may be associated with neurofibromatosis or with a slow-growing tumour adjacent to the sella, such as an optic chiasm glioma, so the "J- shaped" sella turcica is characteristic, but not diagnostic of mucopolysaccharidosis.

The cortical bone of the skull is thickened. The premature closure of the sagittal suture is responsible for the development of macrocephaly with dolicocephaly, plus the metopic perisutural hyperostosis causes a vertical frontal crest. The most important facial anomalies are represented by the lack of pneumatization of mastoid cells and paranasal cavities; the mandible is short and broad, mandibular condyles are undeveloped and the temporomandibolar joint may exhibit limited motion; unerupted and widely spaced teeth can also be found (Fig. 1).

Concerning the thorax, the main abnormality concerns the ribs, which can be "paddle-shaped" or "oar-shaped" because of the widening of the anterior archs and of the tapering of the posterior ones. Other common modifications are small scapulae, usually with flattening of the glenoid
Fig. 3 Spine abnormality. Sagittal T2-weighted fast spinecho image (a); sagittal T1weighted fast spin-echo image (b). The figures show the entire spine of a 14-year-old female with MPS VI: narrowing of the craniocervical junction (white arrow), vertebral bodies deformities (curved white arrow) and nucleus pulposus hypotrophy (white arrowhead) are well depicted; gibbus at thoracolumbar region is also seen
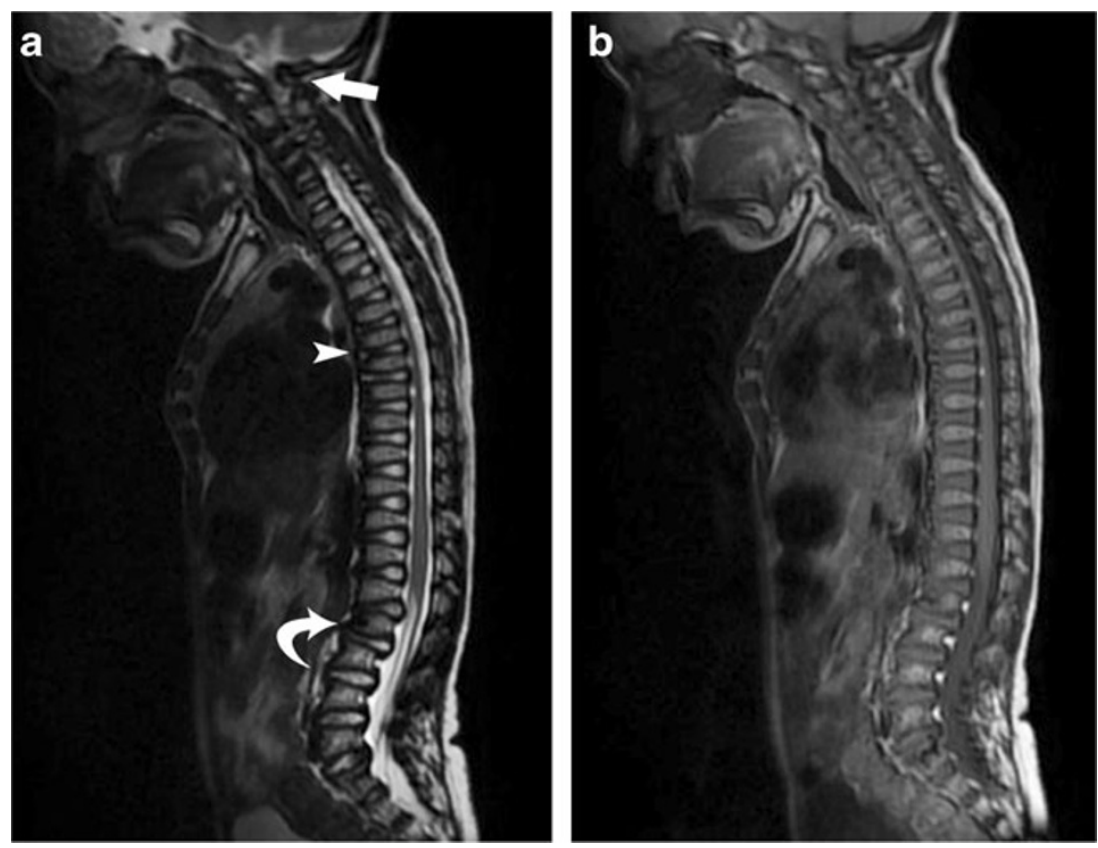
Fig. 4 Deformation of the spine. MRI of the spine of a 12year-old female with MPS VI. Sagittal T2-weighted (a), sagittal T1-weighted (b) and coronal T2-weighted (c) fast spin-echo MRI acquisitions demonstrate marked kyphoscoliotic deformation of the spine, with disc hernias and vertebral bodies deformities
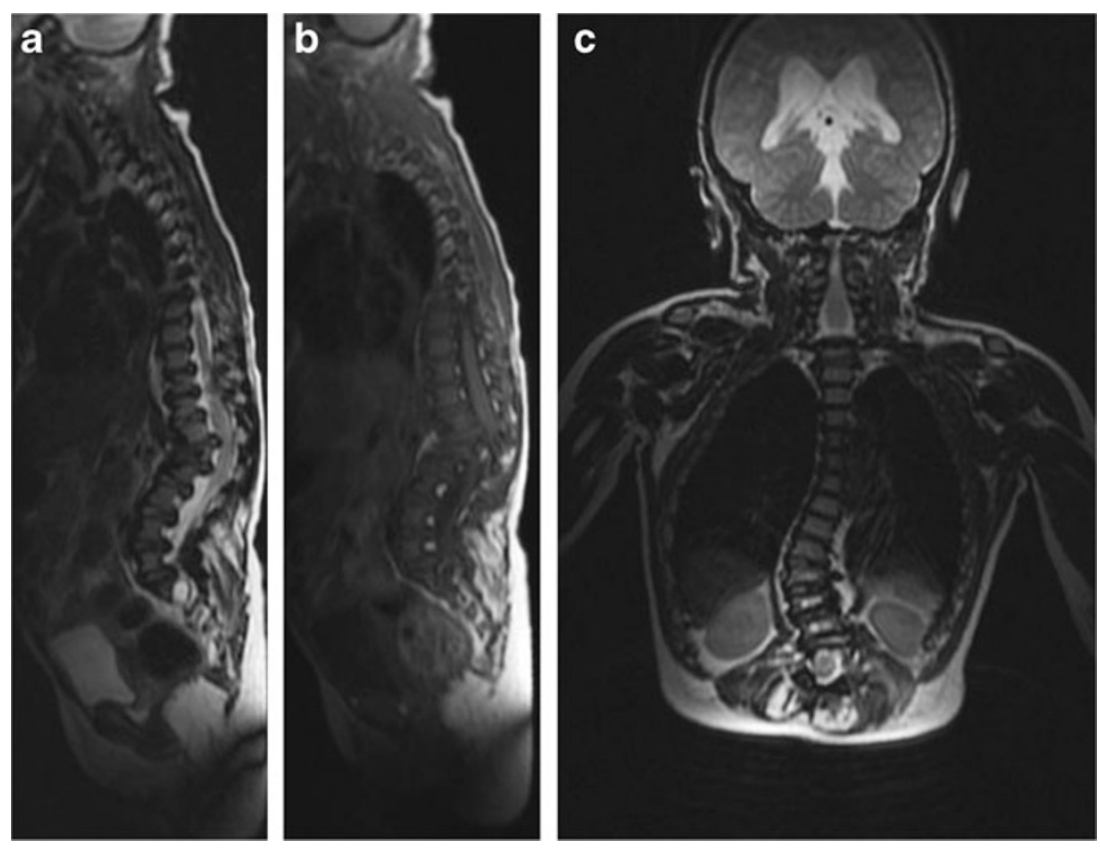

cavities, a short sternum and short and thickened aspect of the clavicles (Fig. 2) [17].

Issues affecting the spine are extremely common (Figs. 3 and 4), and MPS patients may risk important complications due to compression on the spinal cord and emerging nerve roots.

At the craniovertebral junction level, the most important abnormalities are:

- odontoid process displasia-hypoplasia;

- atlantoaxial instability or subluxation;

- periodontoid tissue and ligaments thickening;

- spinal stenosis.
These features represent a critical aspect in MPS (particularly in MPS IV), because if the spinal cord is compressed, cervical myelopathy may result. MRI is more appropriate for the evaluation of spinal cord alterations.

Modifications of the shape of vertebral bodies are very common, resulting in flattened and rounded vertebrae (Fig. 5). At the thoraco-lumbar level the vertebral body can show a deficiency in its anterosuperior corner and, as a consequence, an apparent prolongation of the anteroinferior one, resulting on the lateral X-ray in an "anterior beaking" aspect. When hypoplasia of both anterior corners occurs, the vertebral body is wedge-shaped.
Fig. 5 X-ray of multiplex dysostosis of the spine. A 4year-old child with Hurler syndrome shows vertebral bodies rounded (white arrow, a and b). The "anterior beaking" aspect (white arrowhead, c) with posterior scalloping and the platyspondylia with "wedge-shaped" deformity (curved white arrow, d) are observed in other radiographs of different MPS patients
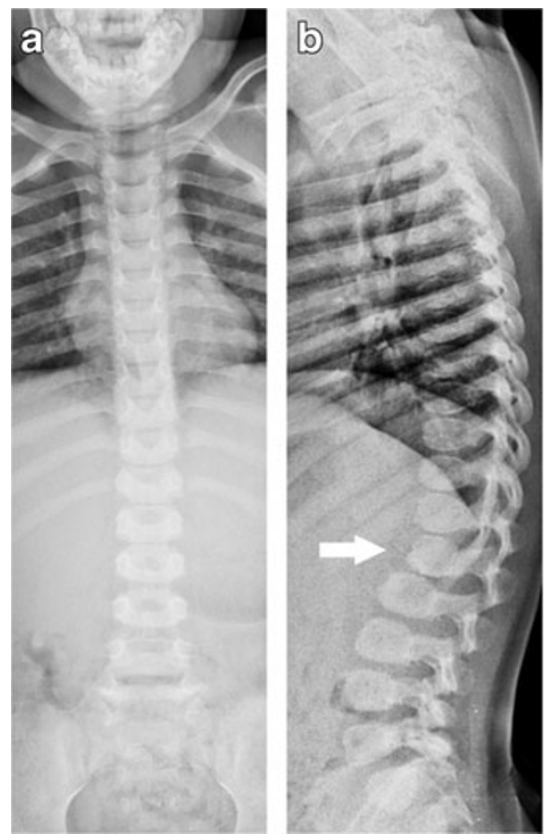
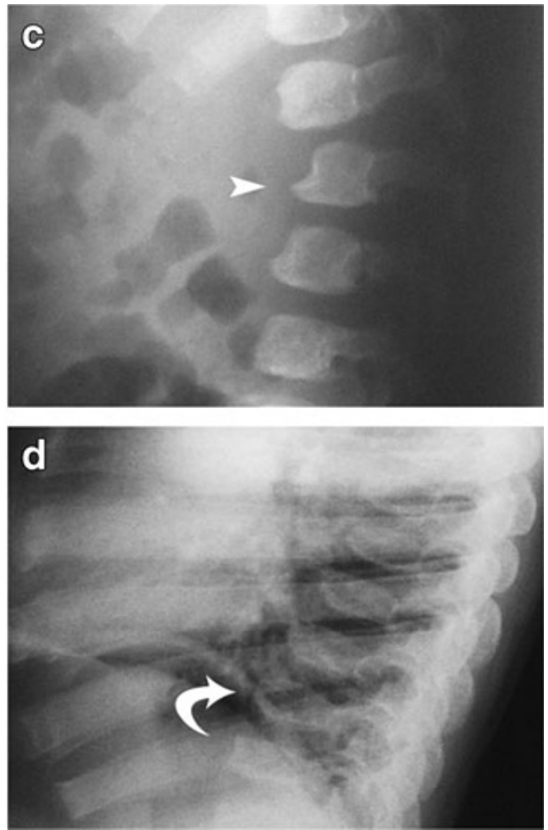
Fig. 6 A 45-year-old female suffering from MPS IV (Morquio disease). Sagittal MRI T2-weighted (a) and T1weighted (b) fast spin-echo acquisitions of the cervicothoracic spine show severe kypho-scoliosis with narrowing of the spinal canal

Fig. 7 Multiplex dysostosis of the pelvis. X-ray of the pelvis in a healthy child (a). Images of the pelvis of MPS patients (bd) showing typical imaging findings of disease: rounded iliac wings, inferior tapering of the ilea with a poorly developed acetabulum, underdeveloped medial portion of the proximal femoral epiphysis, increased coxofemoral joint space and coxa valga are well depicted in b-d

Fig. 8 Appearances of multiplex dysostosis. A 6-yearold boy with MPS II.

Radiographs show several morphological appearances of multiplex dysostosis in long bones, with proximal humeral notching (white arrow, a), long and narrow femoral neck (curved white arrow, b), and frayed and flared tibial metaphyses (c). All segments, particularly those of the upper limb, are short and squat; they also have hypoplastic epiphyses, cortical thinning and flaring of the diaphyseal canal
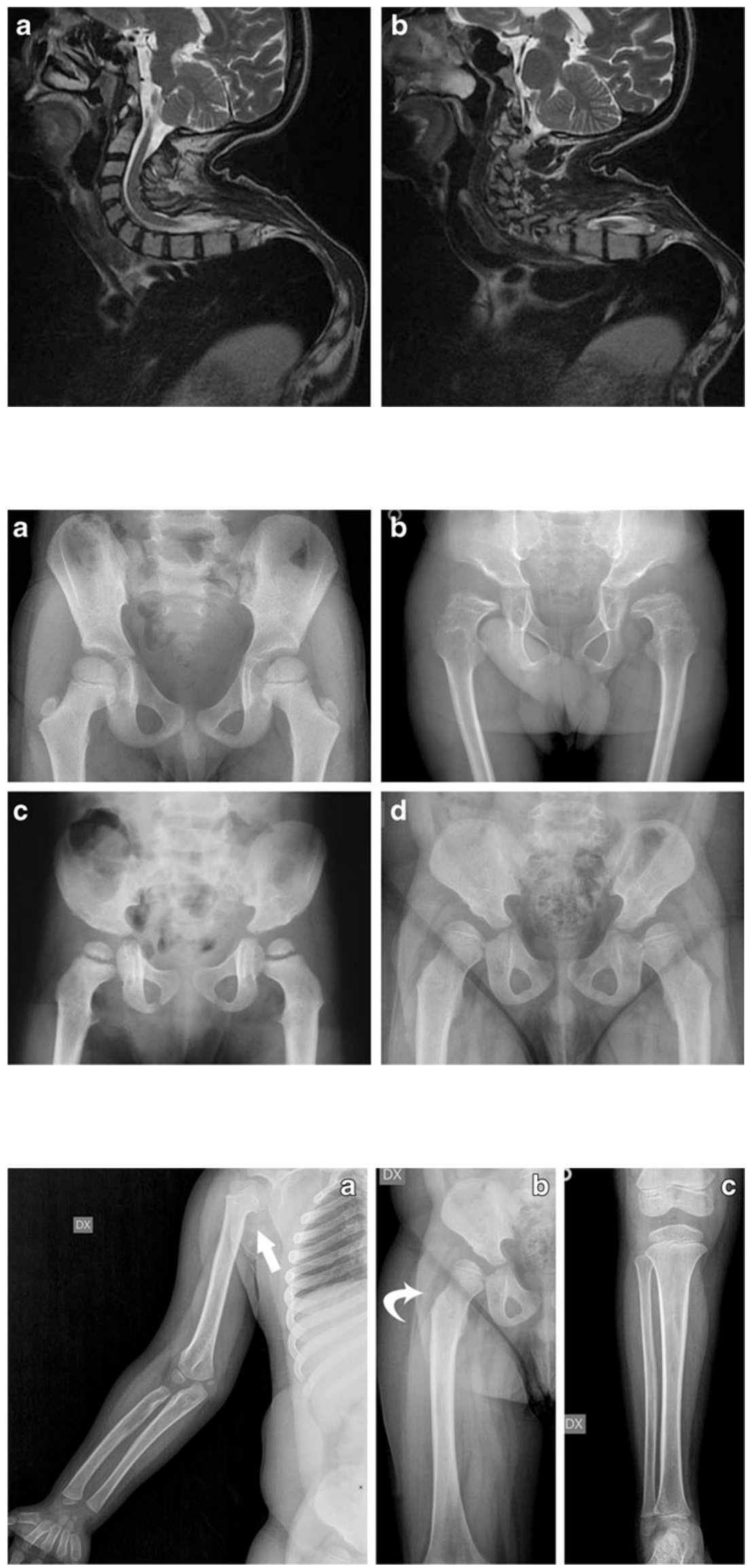
Fig. 9 Multiplex dysostosis. An 8-year-old boy with MPS IH. Anteroposterior femoral $\mathrm{x}$ ray image (a) showing bilateral genu valgum; proximal and distal epiphyses are flared and irregular. Diffuse cortical thinning and osteopenia are also observed (b)

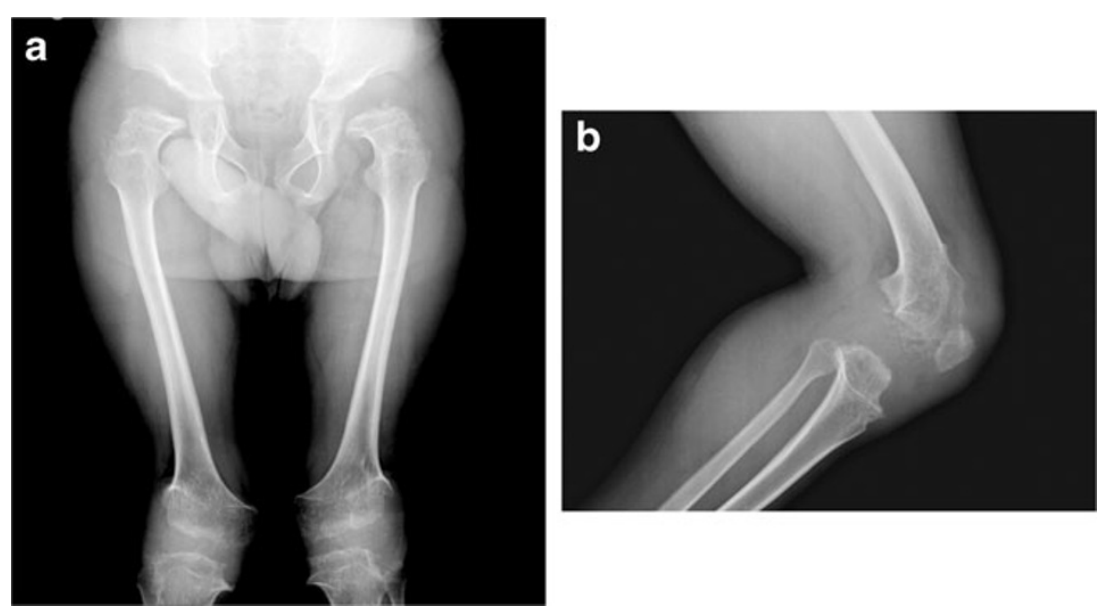

These vertebral morphologic changes may progressively evolve to gibbus deformity (Fig. 6), particularly in MPS I. Scoliosis is usually not bad enough to require surgery; however, myelopathy can represent an indication of the need for surgical treatment [12].

The most common radiological features in the pelvis are rounded iliac wings and inferior tapering of the ileum (Fig. 7) [18]. The alterations of the hip joint can lead to hip dysplasia because of the poor development of the acetabulum and the underdevelopment of the medial portion of the proximal femoral epiphysis. This alteration has not been shown to respond to medical therapy, so for these children surgical reconstruction is often required; the target of this treatment is the optimisation of hip mechanics [12].

\section{Peripheral skeleton}

In MPS patients, the long bones are often characterised by several alterations. Diaphyses are shortened and curved in the distal part; the epiphyses are slightly hypoplastic and thinned cortically with osteoporosis [15]. Other features that can be found are the notching of the proximal part of the humerus, the long and narrow aspect of the femoral neck (Fig. 8), and the hypoplasia of the lateral tibial hemiplate, resulting in genu valgum.

Knees can also be involved, particularly in children with MPS IV and MPS I, developing genu valgum (Fig. 9). This condition is sometimes severe enough to require surgery. In adulthood an advanced state of arthrosis can be recognised because of the considerable delamination of articular
Fig. 10 Dysostosis of the knee. A 15 -year-old female affected by MPS VI. Coronal MRI fast spin echo image (a) and spoiled gradient echo image (b) show an irregularly enlarged growth plate with multiple defects and/ or erosions
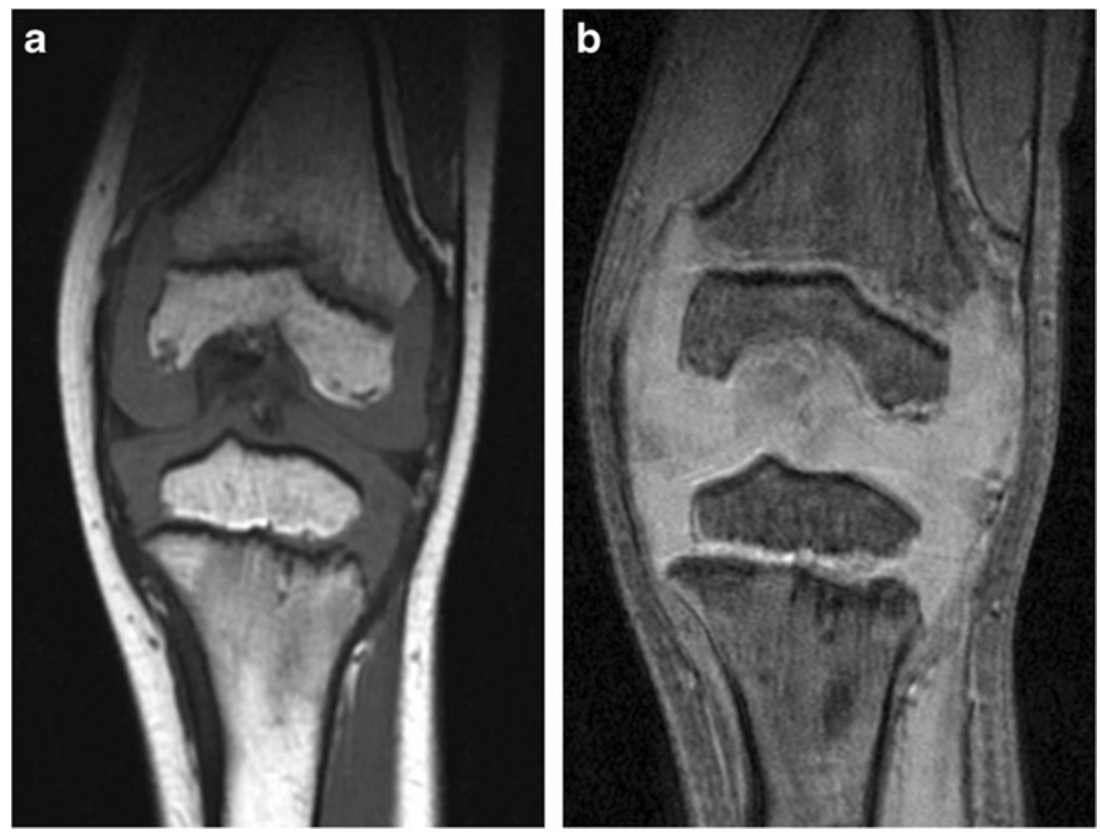
Fig. 11 Dysostosis multiplex of long bones. Dysostosis multiplex of hands and wrists in a 5-year-old boy (b) and in a 15-year-old female (d), both affected by MPS VI (radiographs are compared with normal hands and wrists belonging to subjects of the same age, respectively a and $\mathbf{c}$ ). The main imaging findings encountered in these areas are reported: the V-shaped hypoplastic distal ulna and radius (white arrow), the presence of small irregular carpal bones (curved white arrow), the broad and proximally pointed short metacarpals (white arrowhead) and the bullet-shaped phalanges (empty white arrow)
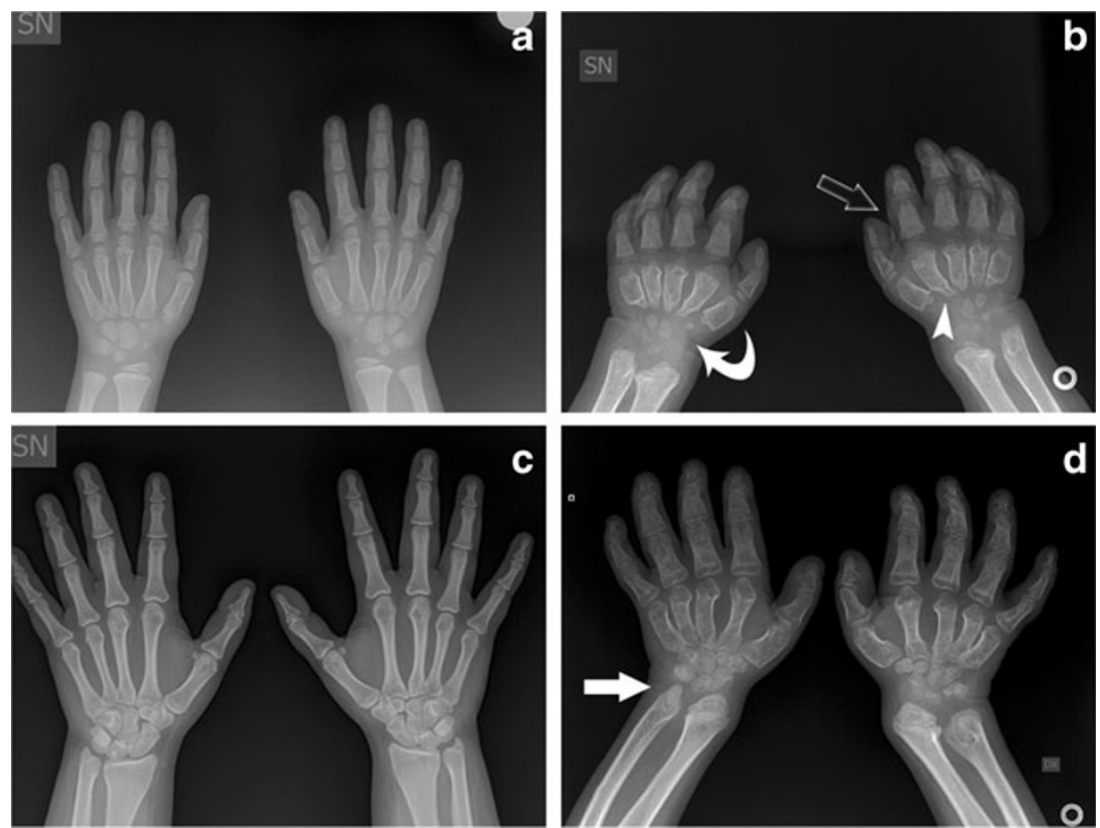

cartilage. These patients are potential surgical candidates for total knee arthroplasty [12].

On MRI images, the growth plate is irregularly enlarged, with multiple defects and erosions well depicted on coronal fast spin-echo proton-density-weighted images (Fig. 10).

Almost all forms of MPS show distortion of the hand (Fig. 11) and foot structure. Carpal and tarsal bones are hypoplastic and irregularly shaped; the metacarpal bones are proximally pointed, shortened and thickened. The functionality of the fingers is compromised because of the bone alterations and the thickening of the subcutaneous tissues, resulting in a failure of a complete extension of the fingers with a "claw hand" deformity $[19,20]$.
Distal ulna and radius can be hypoplastic and have a "Vshaped" appearance; this oblique deformity of the terminal part of both bones results in the alteration of the carpal angle. The alterations in the skeletal anatomy, combined with an excessive GAG deposition in the connective tissue, cause the constriction of the median nerve resulting in carpal tunnel syndrome [21].

\section{Otorhinolaryngological imaging findings}

Abnormal secretions and infiltration of GAG in the mouth, nose, pharynx and larynx result in several otorhinolaryngological manifestations, sometimes the first to appear [22];
Fig. 12 Otorhinolaryngological imaging findings. MDCT temporal bone exam in a 12 year-old female with MPS VI. Axial scans presented from caudal to cranial (a-b-c) demonstrate nasopharyngeal airway and Eustachian tube narrowing (arrow); thickened tympanic membrane (arrowhead); opacification of mastoid cells and left middle air cavity (curved arrow). Other abnormalities, including mucosal thickening of ethmoidal air cells, poor pneumatization of sphenoidal bone and maxillar sinus cavities and impacted teeth, are also depicted. Coronal view of temporomandibular joints (d) shows flattened and deformed mandibular condyles (empty arrow)
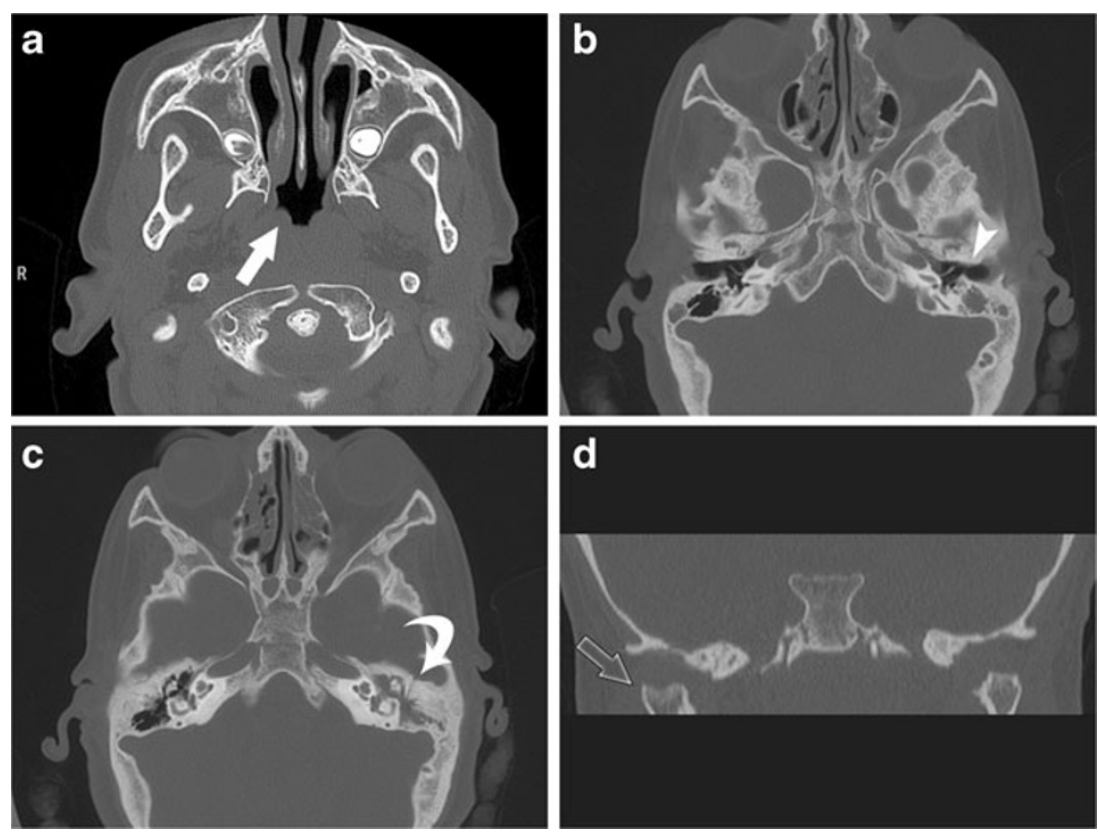
Fig. 13 Neuroradiological imaging findings. A 12-yearold female affected by MPS VI. Axial T2-weighted fast spinecho (a), T2-weighted FLAIR (b) and coronal T2-weighted fast spin-echo (c) images of the brain show symmetrically diffuse increased signal intensity of periventricular white matter, with enlargement of subarachnoid spaces in the middle cranial fossa and ventriculomegaly. Midsagittal T2-weighted scan shows dilated perivascular spaces within the corpus callosum (Fig. 13d)
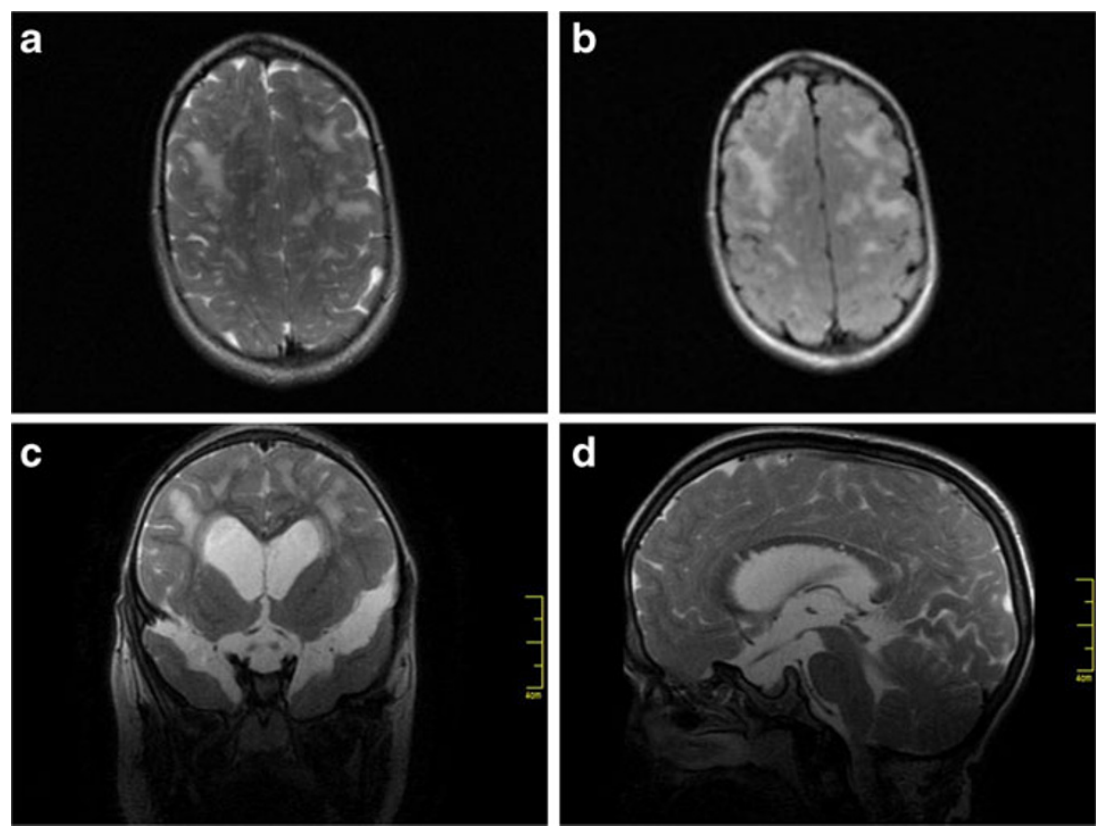

ear, nose, throat and respiratory disorders are very common. The most important otorhinolaryngological problems are rhinitis, otitis media, and upper and lower airway obstruction [23].

Upper airway obstruction may be the consequence of macroglossia, adenotonsillar hypertrophy and chronic nasal discharge in combination with a decreased temporo-mandibular joint mobility. Eustachian tube dysfunction due to enlarged adenoids and inflammation as a consequence of abnormal storage of GAG in the temporal bone are responsible for chronic otitis media and conductive hearing loss [24]. A thickened, retracted tympanic membrane and an increased attenuation of the tympanic cavity and mastoid cells can be observed on multidetector computed tomography (MDCT) images (Fig. 12) [25]. Hearing impairment can also have a sensorineural component because of GAG deposition in the inner ear or central nervous system. The surgical removal of the tonsils and adenoids is often required, even though it is only a temporary solution.

Lower airway obstruction, due to tracheomalacia and narrowing of the tracheal lumen, may lead to pneumonia and acute respiratory insufficiency. The radiologist should know that multiplanar reconstruction of a MDCT scan, usually performed in these patients for the evaluation of the atlanto-axial instability, may be an important tool to
Fig. 14 Neuroradiological imaging findings. A 15-yearold female affected by MPS VI. Axial T2-weighted fast spinecho images (a and $\mathbf{c}$ ) and T2weighted FLAIR acquisition (b) show cribriform focal lesions of periventricular white matter-due to enlarged perivascular spaces - with ventricular enlargement. White matter lesions in the corpus callosum are well depicted by the mid-sagittal T2-weighted fast spin-echo acquisition (white arrowheads, d)
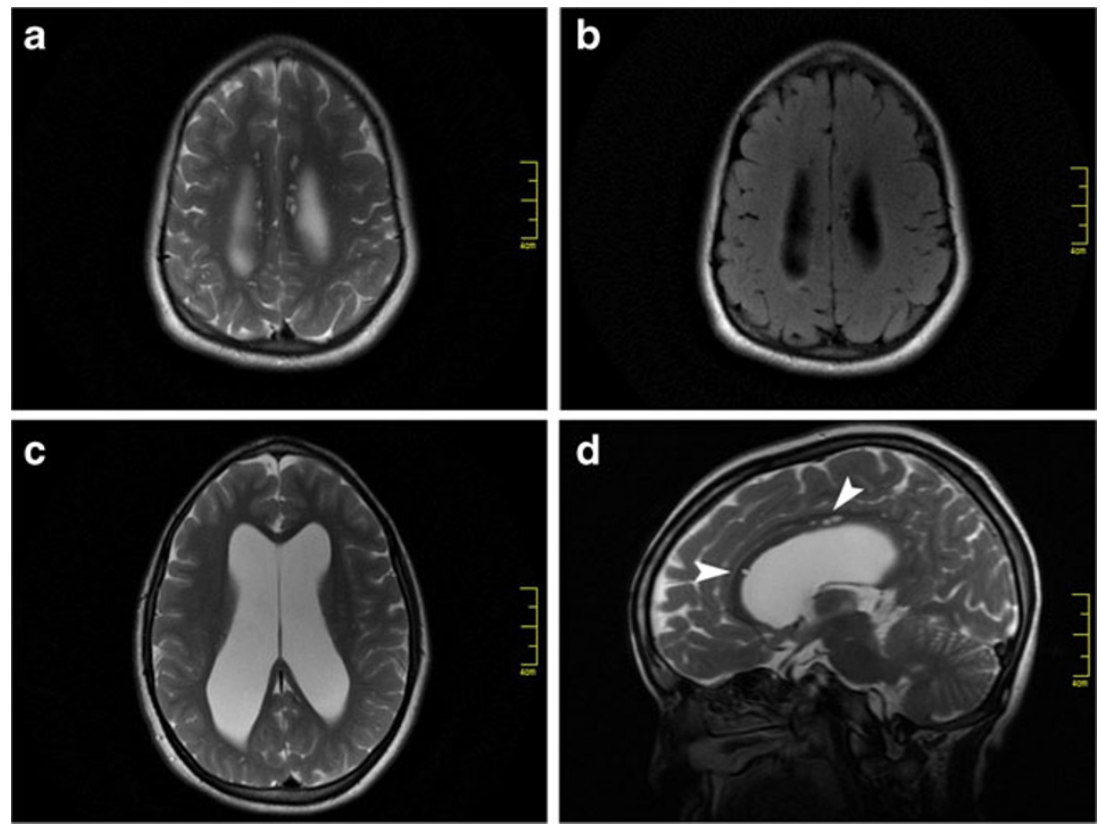

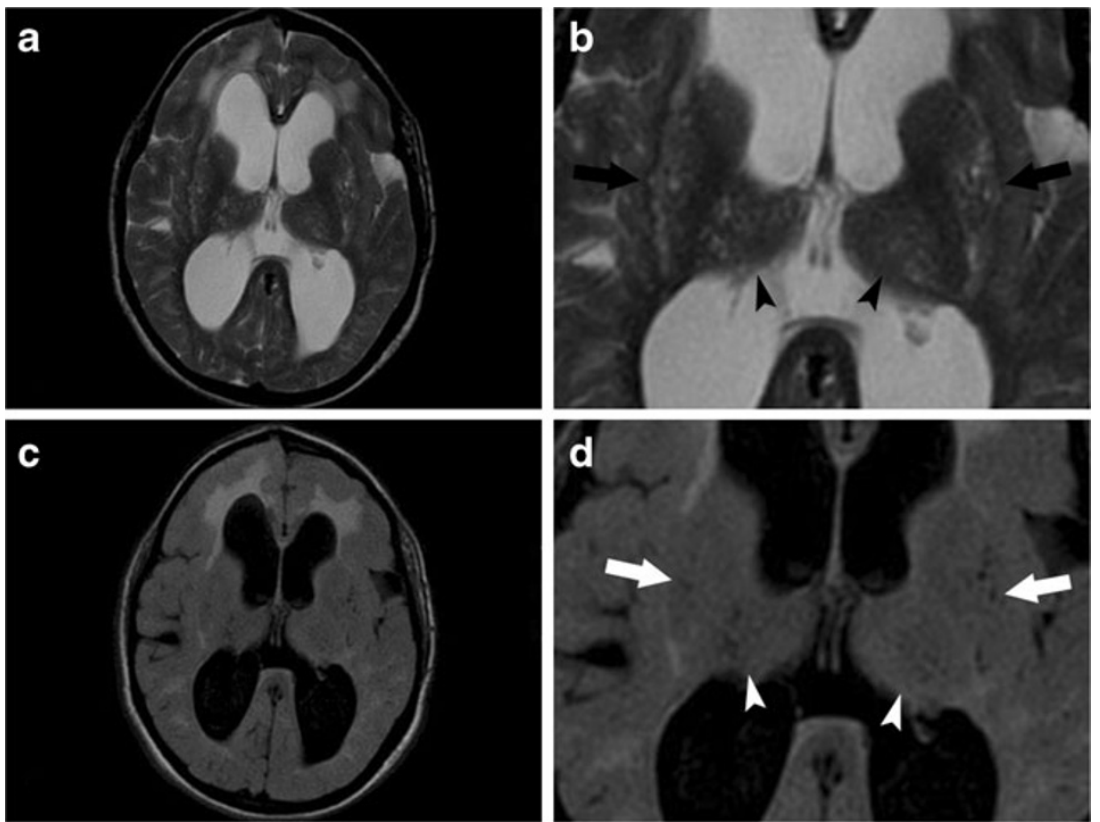

Fig. 15 Neuroradiological imaging findings. Involvement of basal ganglia in an MPS VI patient; the MR exam was acquired when the patient was 17. Axial T2-weighted fast spin-echo (a) brain image obtained at the level of the third ventricle with magnification focused on basal ganglia (b) demonstrating symmetrical focal areas of hyperintensity in the lenticular nucleus (black arrow) and in the

thalamus (black arrowhead) because of enlarged perivascular spaces. On corresponding T2-weighted FLAIR images (c and $\mathbf{d}$ ), these areas (white arrow and white arrowhead) are hypointense. This typical imaging described in the brain of patients with MPS is the "honeycomb-like" appearance. Note also ventriculomegaly and diffuse high signal intensity in the periventricular white matter
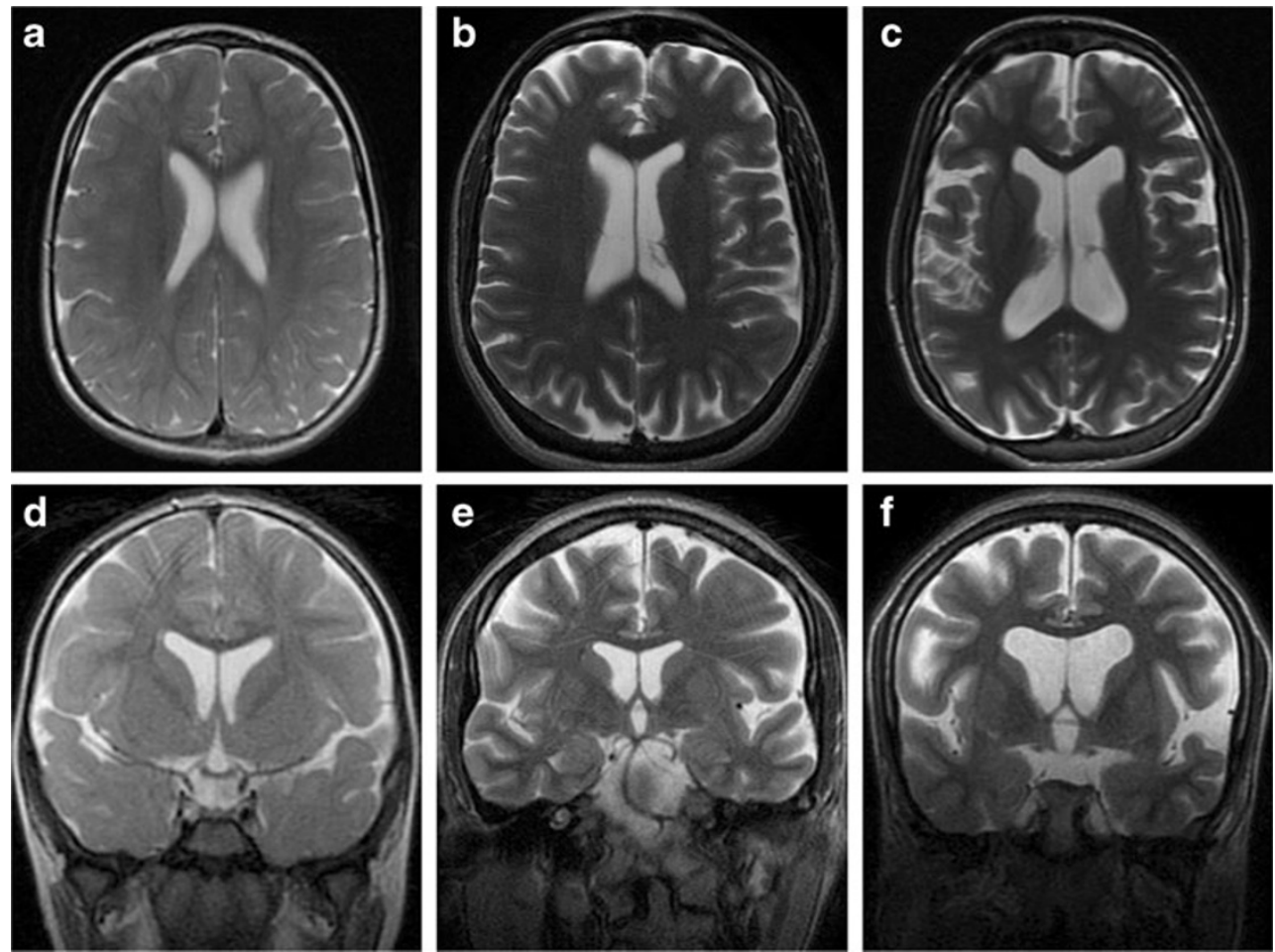

Fig. 16 Neuroradiological imaging findings. Different severity degrees of brain atrophy seen in three MPS patients. Axial (a) and coronal (d) T2weighted fast spin-echo brain images of a 2-year-old male with MPS II show almost normal subarachnoid and ventricular spaces. The T2weighted acquisitions (b and $\mathbf{e}$ ) in a second MPS patient (a 45-year-old female affected by Morquio disease) reveal mild enlargement of subarachnoid spaces. Brain images (c and $\mathbf{f}$ ) in a third MPS patient (an 18- year-old female affected by MPS VI) demonstrate higher enlargement of subarachnoid spaces, with associated dilatation of ventricles. Patients with MPS IV and VI typically have normal intelligence and don't show signs of atrophy until the second decade of life; on the contrary, brain atrophy usually develops earlier in MPS I, II, III and VII, becoming visible during the first few years of life 

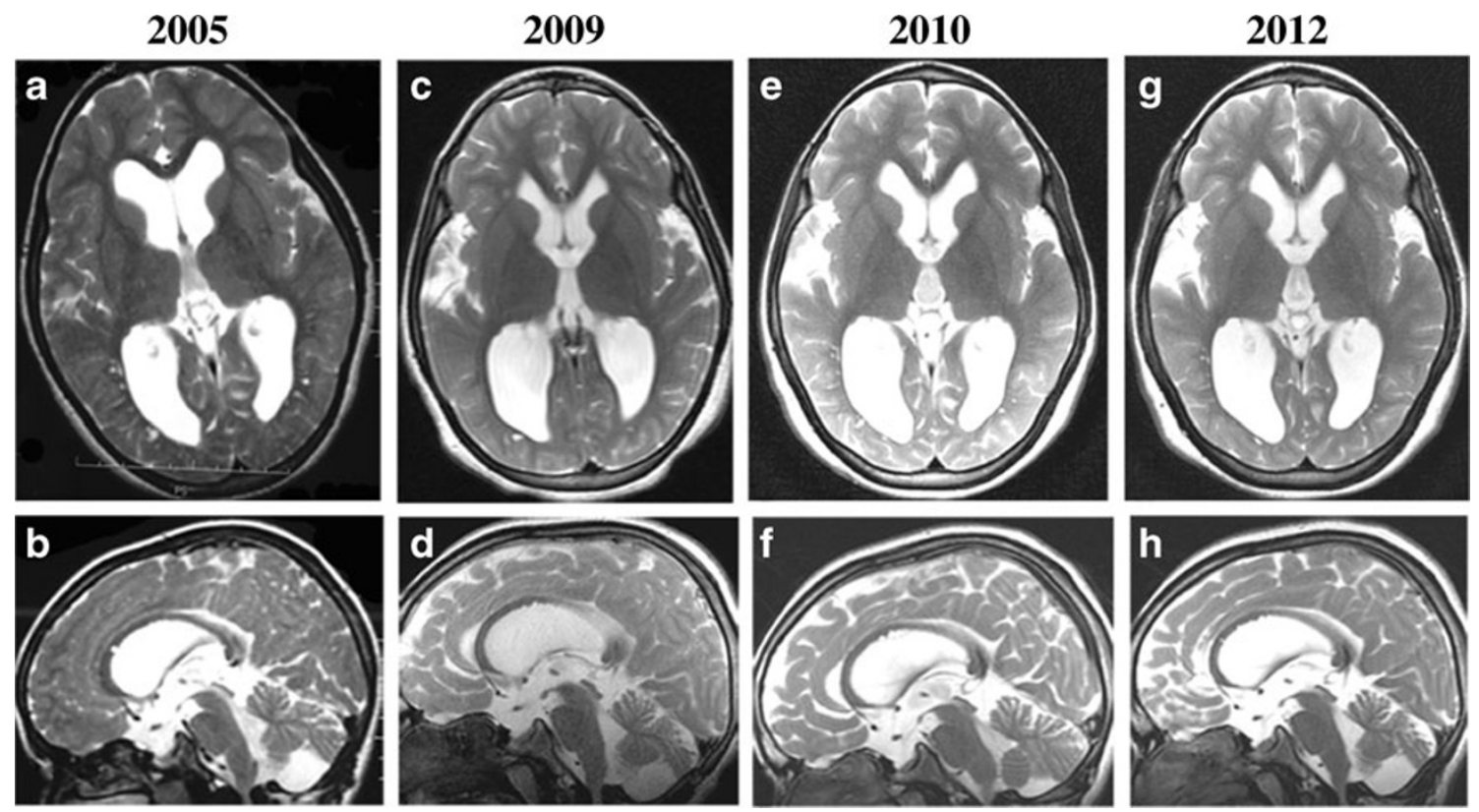

Fig. 17 Neuroradiological imaging findings. Brain atrophy in a patient affected by MPS VI; the patient started treatment with enzyme replacement therapy (ERT) in 2005. The studies were collected from 2005 (when she was 11 years old) to 2012 (at the age of 17). The patient shows a moderate degree of brain atrophy, with mild enlargement of the Sylvian fissure on axial images $(\mathbf{a}, \mathbf{c}, \mathbf{e}, \mathbf{g})$; on sagittal acquisitions there are some focal lesions along the corpus callosum and an enlargement of cisterna

assess the status of the whole airway passage. Anaesthesiologists could use this information to improve their preoperative airway management [26-28]. Sometimes it may be necessary to perform a tracheostomy in order to ensure airway safety $[24,29]$.

magna (b, d, f, h). The brain atrophy does not show significant progression through the different MR examinations. Despite encouraging results observed in patients with MPS II, the ERT therapy does not seem to improve the appearance of neuroradiological imaging findings; the enzymes do not cross the haematoencephalic barrier. However, new evidence is needed in order to investigate the progression of neuroradiological imaging findings after treatment

Neuroradiological imaging findings

The pathogenetic substrate of central nervous system involvement lies in the abnormal accumulation of

Fig. 18 Involvement of the craniocervicaljunction. Sagittal T2-weighted fastspin-echo MRI acquisitions at the craniocervical junctioninapatientaffected by MPS VIbefore(a) and after(c) the decompressivesurgical procedure. Magnifications (b and d) show a T2 hypointenselesionsurroundingthe odontoid process (whitearrowhead, $\mathbf{b})$ with marked narrowing of the foramen magnum and cord compression; the stenosis improved moderately after surgery. Note also the abnormal J-shaped sella(whitearrow, d)
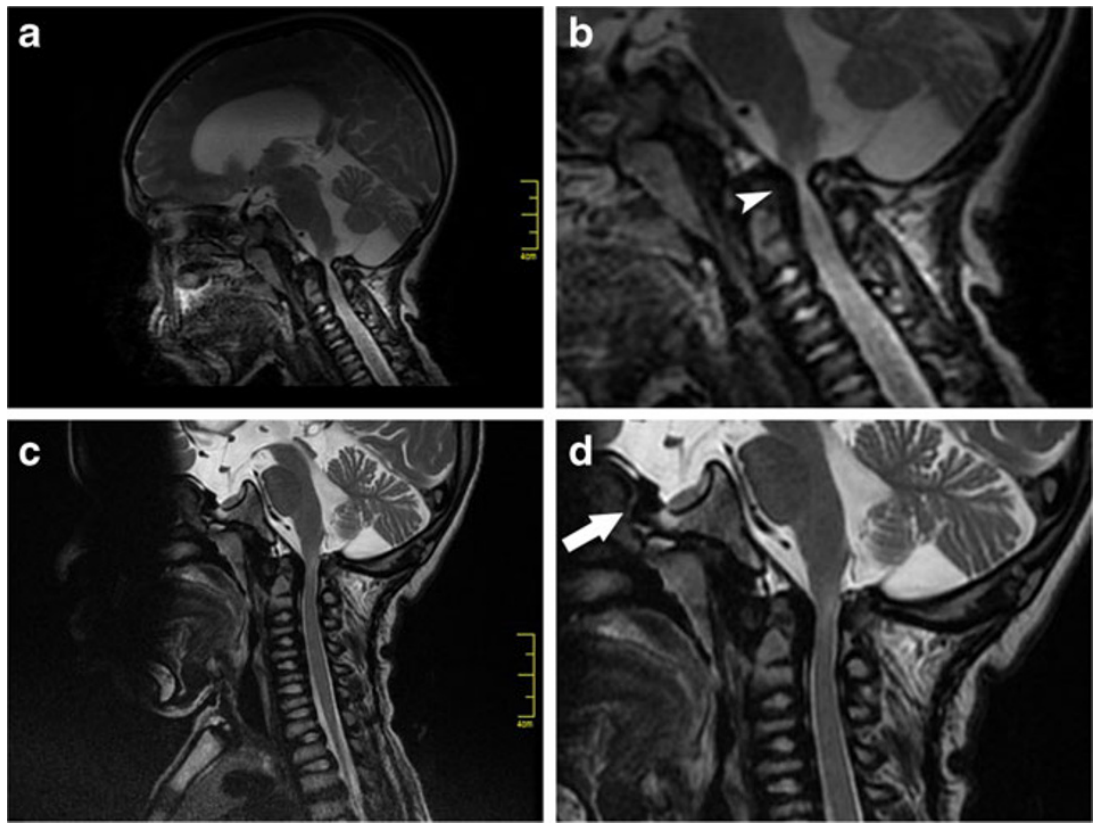
mucopolysaccharides within perivascular spaces and neuroaxonal units with an adversely affected myelin turnover [30].

On the basis of MRI findings a large spectrum of severity can be recognised, from negligible to severe. Here we describe the main neuroradiological features: abnormal signal intensity in the white matter and in the basal ganglia, dilatation of periventricular spaces, widening of cortical sulci, brain atrophy and enlargement of extraventricular spaces, and spinal cord compression. Recently, a few cases of closed cephalocele have been reported in the literature [31].

\section{Abnormal signal intensity in the white matter and in the basal ganglia}

One of the typical neuroradiological imaging findings is represented by focal or diffuse white matter lesions, detected as areas of high signal intensity on T2weighted sequences. These alterations show an increase with aging, becoming more extensive with time.

Diffuse white matter lesions usually show a symmetrical periventricular distribution, although they can also be found as patchy lesions in the subcortical region (Fig. 13). They derive from the delay of myelination in young children and progressive demyelination in the course of the disease; these lesions can also reflect gliosis $[32,33]$. Focal white matter lesions consist of multiple small spot-like areas isointense to the cerebrospinal fluid (CSF) on fluid attenuated inversion recovery (FLAIR), T2-weighted and T1-weighted sequences (Fig. 14) because of periventricular space enlargement.

The corpus callosum, best depicted on sagittal images, is sometimes the only location of these lesions, although they can also be encountered in the parietal and occipital lobe, in the basal ganglia, in the thalamus and at the grey-white matter junction level [32-34]. A typical imaging feature in the brain of patients with MPS is the "honeycomb-like" appearance in the basal ganglia and thalami (Fig. 15); this imaging finding has been observed in patients with MPS I, II and IIIB [35, 36]. Two theories have been proposed to explain the pathogenesis of basal ganglia involvement; the first concerns the accumulation of GAGs in neurons and astrocytes, leading to neuronal loss and demyelination; another theory maintains that the basal ganglia appearance could be related to an increase of fluid content in the periventricular spaces.

The pathogenesis of enlargement of perivascular spaces is not entirely clear [34]. Two main hypotheses have been formulated: accumulation of GAG around vessels [37] and impairment of cerebrospinal fluid reabsorption (caused by the deposit of mucopolysaccharides in the leptomeninges) [32].

In addition, in the white matter of parietal and occipital lobes, multifocal variable-sized areas of high signal intensity-which doesn't match that of cerebrospinal fluid-may be detected on FLAIR and T2-weighted sequences; these lesions, probably due to gliosis, tend to become extensive and confluent.

\section{Hydrocephalus and brain atrophy}

Ventricular enlargement, with or without involvement of the subarachnoid spaces, is a common finding in patients with MPS (Figs. 13, 14, 15, 16 and 17). Communicating hydrocephalus may be the consequence of either diffuse brain atrophy or reabsorption failure of cerebrospinal fluid due to dysfunction of the arachnoid granulations. A cysticappearing enlargement of the cerebellomedullary and/or suprasellar cisterna has been described [34].

The atrophy of the brain, probably due to neuronal death and myelin loss, is a common feature in MPS and is seen as widened subarachnoid spaces and enlargement of the
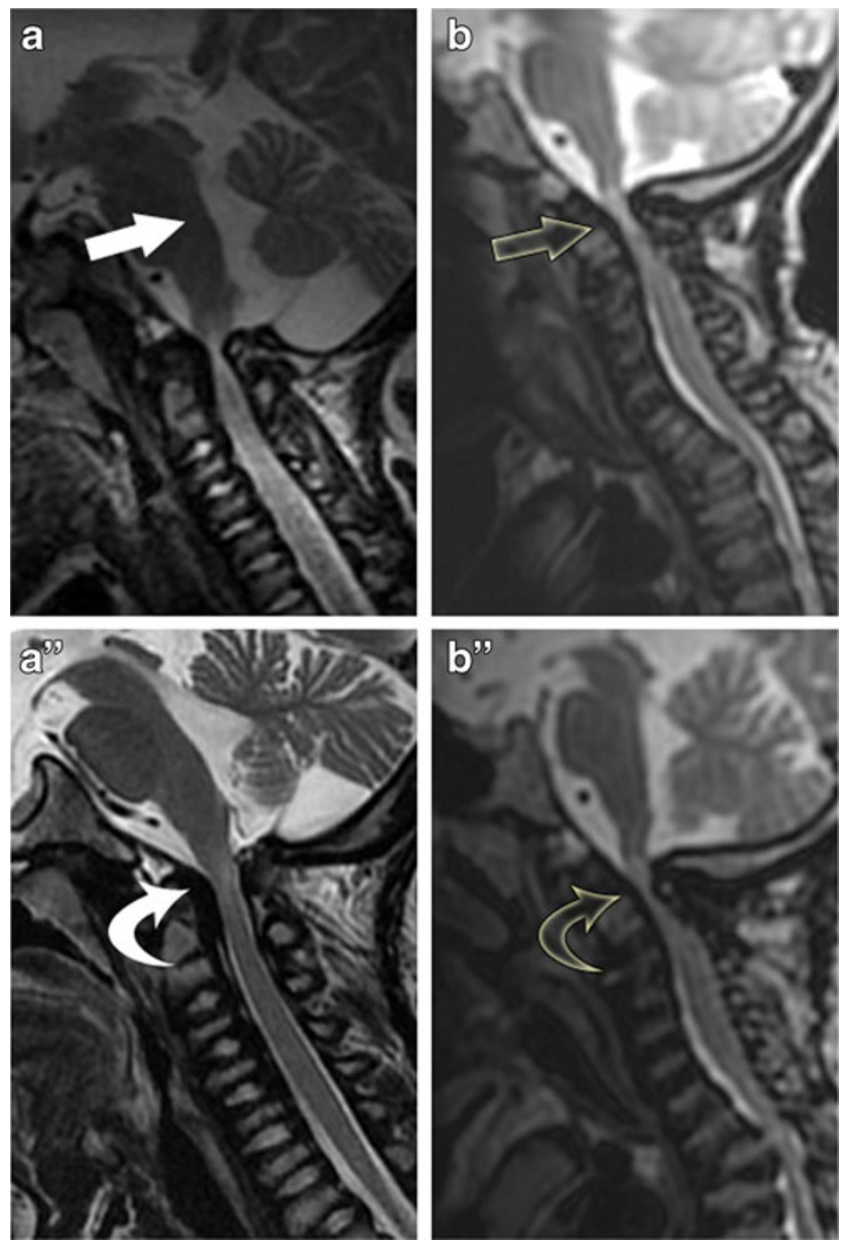

Fig. 19 Involvement of the craniocervical junction: recurrence after surgery. Craniocervical junction appearance in an MPS VI patient before (a) and after (a") the decompressive surgical procedure: note the improvement in size of the craniocervical junction, with enlargement of subarachnoid spaces after the surgical procedure. b and b" show recurrence of stenosis of the craniocervical junction in an MPS IV patient 3 and 12 years respectively after surgery; the recurrence is due to progression of GAG accumulation 
Fig. 20 MRS. (Legend: $\mathrm{mIns}=$ myo-inositol; Cho = choline; $\mathrm{Cr}=$ creatine; $\mathrm{NAA}=\mathrm{N}$-acetylaspartate). Multivoxel MRS performed on an MPS VI patient; after post-processing analysis, two spectroscopic graphics are shown in a and $\mathbf{c}$ (corresponding voxels in $\mathbf{b}$ and d). The $\mathrm{mIns} / \mathrm{Cr}$ ratio was found to have slightly increased in the white matter lesion and in the gray matter area (respectively values of 0.68 and 0.59 ). As reported by Vedolin et al. [39], cerebral GAG deposition induces changes in glial cells, with a consequent increase in the $\mathrm{mIns} / \mathrm{Cr}$ ratio
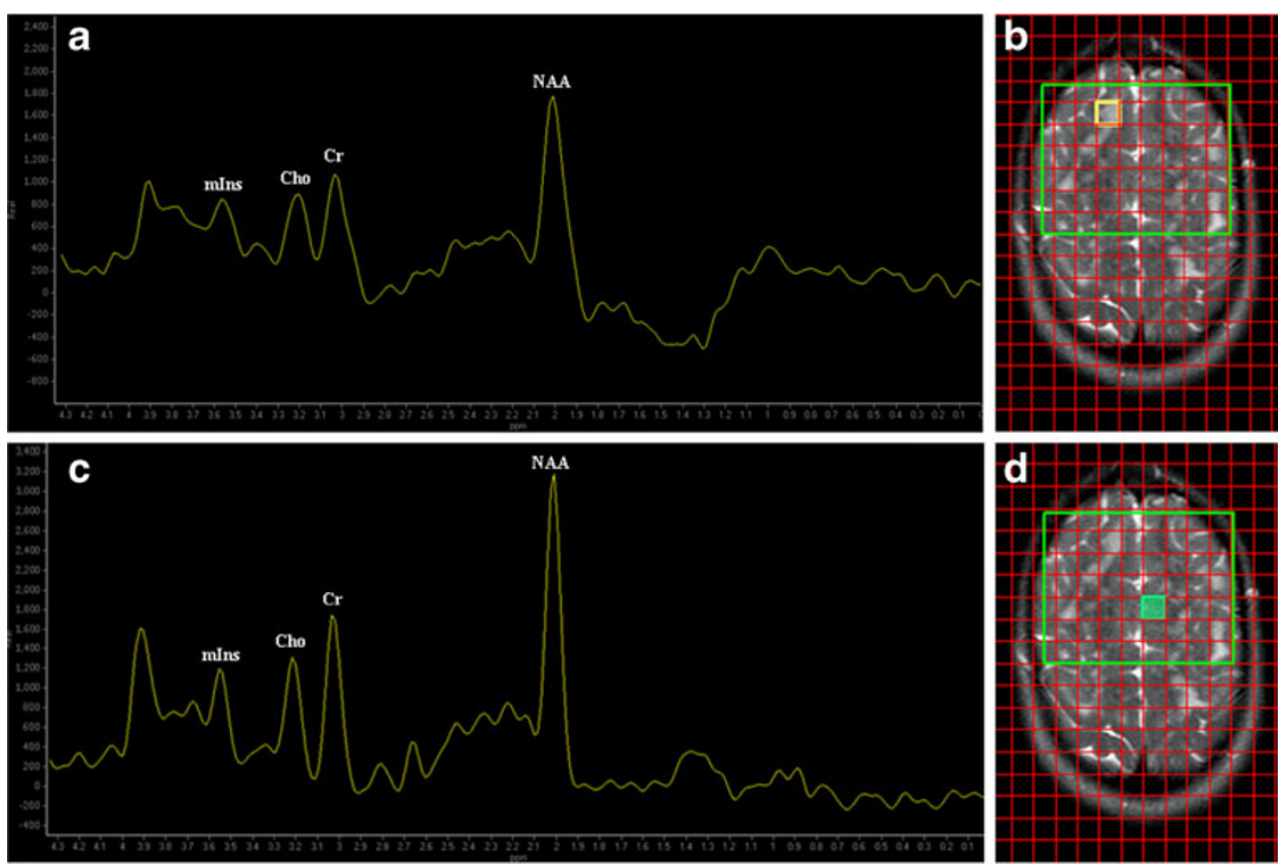

cortical sulci. The neuronal death could be explained by ischaemic damages due to the progressive accumulation of GAG in blood vessels [38]; on the other hand, the neuronal death could be caused by direct intracellular storage of GAG.

The MRI evaluation of these findings is a useful marker of axonal loss [16]. Brain atrophy usually develops earlier in MPS I, II, III and VII, becoming visible during the first few years of life; on the contrary, patients with MPS IV and VI typically have normal intelligence and don't show signs of atrophy until the second decade of life.
The different degree of brain atrophy has been recently evaluated for monitoring disease progression and response to therapy $[15,33]$; these authors reported a classification using the method introduced by Lee et al. [38]. Brain atrophy could be:

- absent

- mild (widening of the sylvian and interhemispheric fissures $<3 \mathrm{~mm}$, but not all sulci are involved)

- moderate (widening of all fissures and sulci between 3$5 \mathrm{~mm}$ with visualisation of the entire mesencephalic cistern)
Fig. 21 Optic nerve involvement. Optic nerve involvement in the same MPS patient as Fig. 14: axial (a), coronal (b) and sagittal (c) T2weighted fast spin-echo acquisitions show widening of the optic nerve sheath, with enlargement of the perineural CSF space; angulation of the right optic nerve is also observed
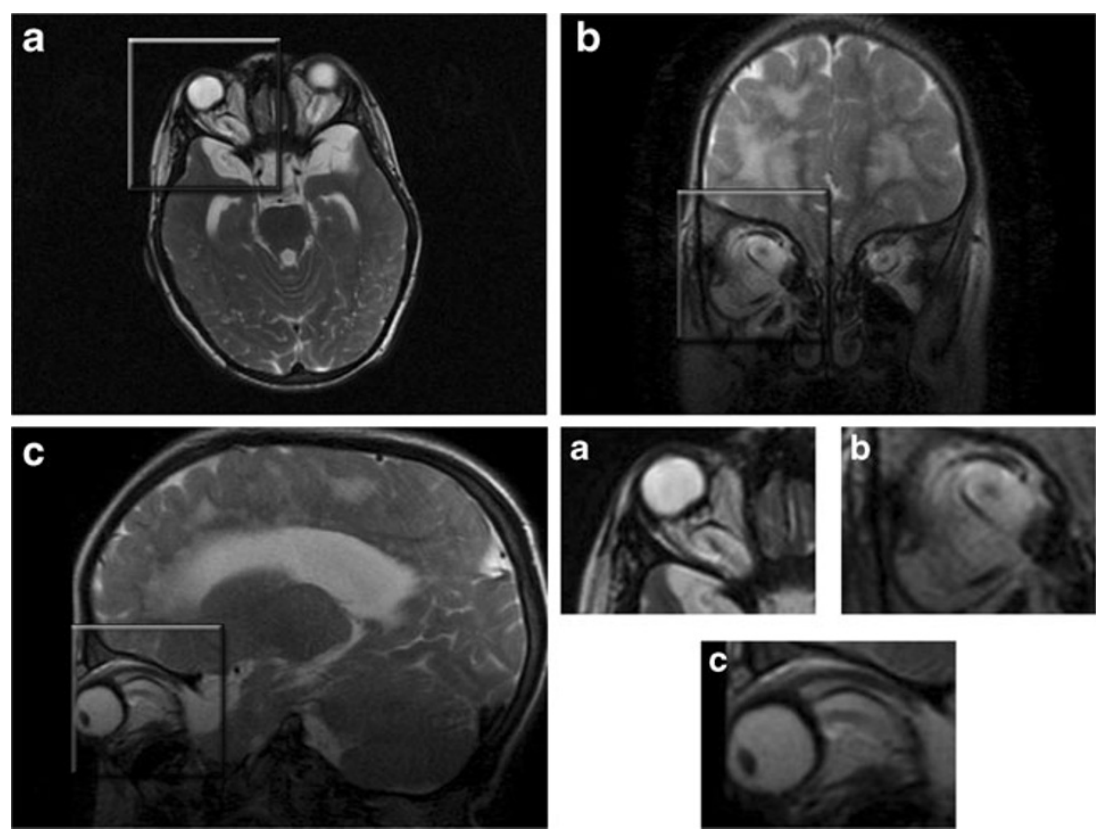
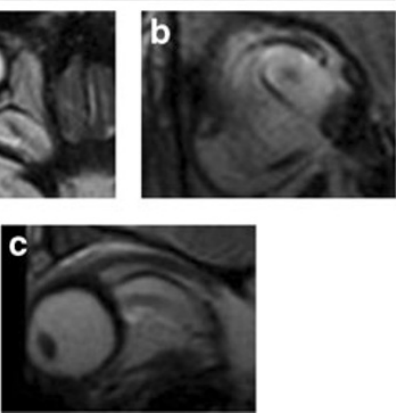
Fig. 22 Closed encephalocele in MPS VI. MRI of the brain of an 18-year-old girl affected by MPS VI. Axial T2-weighted (a), coronal T2-weighted (b), sagittal T2-weighted (c) and sagittal T1-weighted (d) acquisitions demonstrate a closed cephalocele (white arrows)
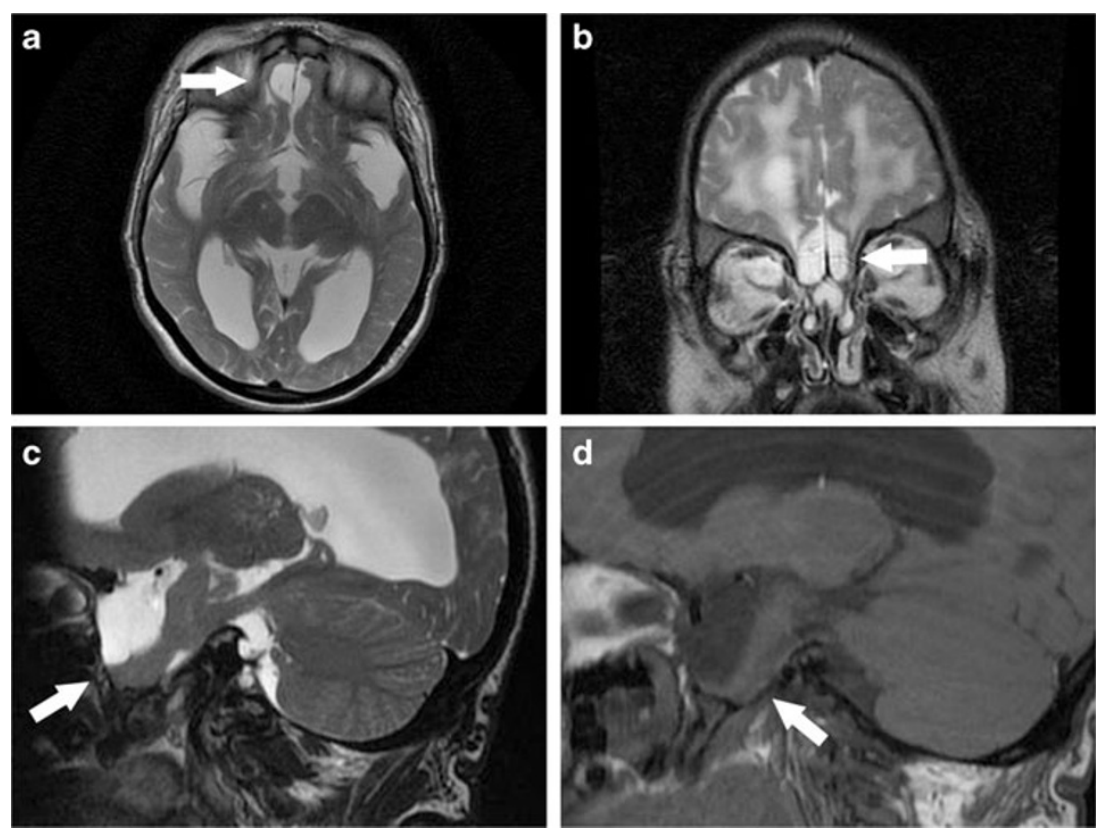

- severe (widening of all fissures and sulci $>5 \mathrm{~mm}$ with definite loss of cortex and white matter).

A strong correlation was found between severity of brain atrophy and cognitive impairment in MPS [33, 39], whereas other authors did not find the same correlation [40].

\section{Spinal cord compression}

Compression of the spinal cord most frequently occurs at the atlanto-axial (C1-C2) joint (Figs. 18 and 19), especially affecting patients with MPS IV and VI. Many of these patients suffer from several craniocervical junction abnormalities due to structural defects involving the spine. The most important one is atlanto-axial subluxation, which is the result of several causes: laxity of the transverse ligament, dural thickening resulting from deposition of collagen and GAGs, hypoplasia or absence of the odontoid, anterior soft tissue mass of the odontoid (representing a combination of

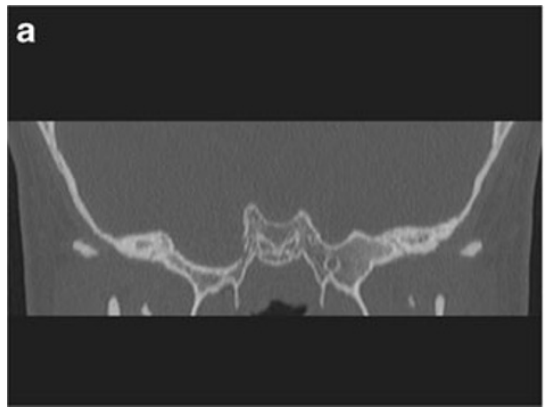

Fig. 23 Closed encephalocele in MPS VI. Closed encephalocele in patient affected by MPS VI (same patient as in Fig. 12). Coronal MDCT image of middle cranial fossa (a), obtained at the level of the pterygoid processes, revealing a bone depression of the right great unossified fibrocartilage and reactive changes) and indentation of the posterior arch of $\mathrm{C} 1$ [33]. The anomaly of the odontoid process ranges in severity from total aplasia to a triangular-shaped configuration with a loss in vertical height and a broad-based tip [41]. Chronic subluxation of the C1C2 level may lead to a ligamentous hypertrophy and to further narrowing in the region of the craniocervical junction with the consequence of additional cord compression. Another cause of cord compression in these patients is gibbous formation in the thoracic spine, resulting from the malformations of vertebral bodies (most common in Morquio disease). Compressive cervical myelopathy is a critical problem since the involvement of the bulbar-spine junction may lead to central respiratory failure [33].

\section{Magnetic resonance spectroscopy (MRS)}

MRS (Fig. 20) is a non-invasive imaging technique able to provide information about tissue molecular structures. Brain

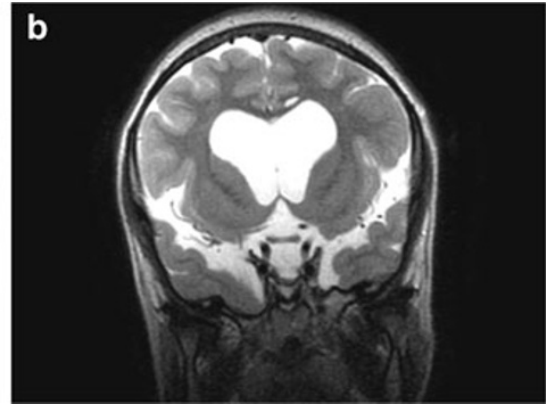

wing of the sphenoid. The corresponding coronal T2-weighted MRI image (b) demonstrates the pouch filled with cerebrospinal fluid and brain parenchyma 
application leads to revealing the concentration of brain metabolites and can be used to monitor biochemical changes in brain diseases.

Numerous studies have suggested a contribution of MRS to mucopolysaccharidoses assessment $[42,43]$.

Davison et al. [42, 43] found a reduction of the white matter $\mathrm{N}$-acetylaspartate/creatine $(\mathrm{NAA} / \mathrm{Cr})$ ratio in MPS IVa and II proportional to cognitive indices and to disease progression [42, 43], while Vedolin did not find a significant difference in the NAA/Cr ratio between patients with and without cognitive impairment; Vedolin found instead an elevated myo-inositol/creatine $(\mathrm{mIns} / \mathrm{Cr}$ ) ratio in patients with cognitive impairment [39]. The increase in the mIns/Cr ratio is interpreted as a possible marker of glial activity (Fig. 20).

Takahashi et al. [44] measured presumptive mucopolysaccharides in white matter lesions and in white matter without lesions and compared the presumptive MPS/Cr ratios before and after bone marrow transplantation (BMT) [44]. They found a reduction in mucopolysaccharides in white matter without lesions after the BMT; they also found a correlation between mucopolysaccharide accumulation and neuronal damage resulting in a decreased NAA/Cr ratio [44].

In summary, new evidence is needed in order to understand the real value of MRS in the evaluation of neurological involvement.

\section{Miscellaneous}

Another commonly found sign in MPS patients is macrocephaly, resulting from hydrocephalus combined with abnormal accumulation of incompletely broken down GAGs within the brain, meninges and skull. Macrocephaly is diagnosed when the circumference of the head exceeds normal values by more than two standard deviations. Other dysmorphic features, such as frontal prominence, scaphocephaly, a short neck and enlarged tongue, can be observed.

Several orbital abnormalities can be found: thickening of the sclera and of the optic nerve sheath, optic canal narrowing and optic nerve atrophy (Fig. 21).

Finally, another imaging features reported in literature [31] is the closed encephalocele (Figs. 22 and 23); regarding this point, the presence of parenchymal/meningeal herniation at the level of the anterior or middle cranial fossa has been described as a characteristic neuroradiological feature of patients affected by MPS II. Instead of the term "meningoencephalocele," which indicates the herniation of brain and/or meningeal tissue through a bone defect, the term "closed cephalocele" has been proposed to describe this skull abnormality because the protrusion of intracranial structures occurs without a detectable bone defect. The etiopathogenesis of this further manifestation seems to be related to an increased intracranial pressure and/or an altered bone maturation process. CT and MRI reveal a variablesized pouch filled with brain parenchyma and cerebrospinal fluid, delimited by a bone wall and usually located in the anterior cranial fossa at the level of the lamina cribrosa as a weak area of the skull. The radiologist should look out for the presence of a closed cephalocele because it may interfere with rhinosurgery and cause epilepsy [31].

\section{Conclusion}

Knowledge of radiological and neuroradiological appearances of MPS is essential for radiologists. Skeletal X-ray and MRI may show specific features in MPS patients, although it is not possible to accurately differentiate between MPS types based on skeletal and neurological characteristics. The evaluation of these imaging findings is useful for suggesting and supporting MPS as a possible diagnosis, usually obtained by laboratory analysis, for monitoring the chronic and progressive course of the disease, for surgical and medical planning and for assessing the impact of therapy.

Acknowledgments The authors would like to thank AIFA (Agenzia Italiana del Farmaco) for its support in the field of research and especially for financing study protocol no. FARM6CC747. The authors declare no potential conflict of interest. This paper has been partially presented as "educational exhibit" at the ECR 2012 Congress.

Open Access This article is distributed under the terms of the Creative Commons Attribution License which permits any use, distribution, and reproduction in any medium, provided the original author(s) and the source are credited.

\section{References}

1. Coutinho MF, Lacerda L, Alves S (2011) Glycosaminoglycan storage disorders: a review. Biochem Res Int 2012:471325. doi: $10.1155 / 2012 / 471325$

2. Muenzer J (2004) The mucopolysaccharidoses: a heterogeneous group of disorders with variable pediatric presentations. J Pediatr 144(5 Suppl):S27-S34. doi:10.1016/j.jpeds.2004.01.052

3. Wraith JE (1995) The mucopolysaccharidoses: a clinical review and guide to management. Arch Dis Child 72(3):263-267. doi:10.1136/adc. 72.3 .263

4. Lala-Gitteau E, Majzoub S, Labarthe F, Blesson S, Pisella PJ (2007) Ophthalmologic signs in mucopolysaccharidoses: two case reports. J Fr Ophtalmol 30(2):165-169

5. Nelson J, Shields MD, Mulholland HC (1990) Cardiovascular studies in the mucopolysaccharidoses. J Med Genet 27(2):94 100. doi:10.1136/jmg.27.2.94

6. Mostefa Kara M, de Groote P, Abboud G, Tillie-Leblond I, Mouquet F (2011) Cardiac magnetic resonance imaging of mucopolysaccharidosis type II cardiomyopathy. Int J Cardiol 147(1):170-171. doi:10.1016/j.ijcard.2010.10.089 
7. Golda A, Jurecka A, Tylki-Szymanska A (2011) Cardiovascular manifestations of mucopolysaccharidosis type VI (MaroteauxLamy syndrome). Int J Cardiol 158(1):6-11. doi:10.1016/ j.ijcard.2011.06.097

8. Beck M, Muenzer J, Scarpa M (2010) Evaluation of disease severity in mucopolysaccharidosis. J Pediatr Rehab Med 3(1):39-46. doi:10.3233/PRM-2010-0100

9. Beck M (2007) New therapeutic options for lysosomal storage disorders: enzyme replacement, small molecules and gene therapy. Hum Genet 123:1-22. doi:10.1007/s00439-006-0280-4

10. Polgreen LE, Miller BS (2010) Growth patterns and the use of growth hormone in the mucopolysaccharidoses. J Pediatr Rehabil Med 3(1):25-38. doi:10.3233/PRM-2010-0106

11. Lanza ML, Attinà G, Palmucci $\mathrm{S}$, Mauro LA, Belfiore G, Barone R, Fiumara A, Sorge G, Ettorre GC (2012) Imaging findings of mucopolysaccharidosis EPOS European Congress of Radiology, Vienna doi:10.1594/ecr2012/C-2180

12. White KK, Harmatz P (2010) Orthopedic management of mucopolysaccharide disease. J Pediatr Rehabil Med 3(1):47-56. doi:10.3233/PRM-2010-0102

13. Rasalkar DD, Chu WC, Hui J, Chu CM, Paunipagar BK, Li CK (2011) Pictorial review of mucopolysaccharidosis with emphasis on MRI features of brain and spine. Br J Radiol 84(1001):469 477. doi:10.1259/bjr/59197814

14. Simonaro CM (2010) Cartilage and chondrocyte pathology in the mucopolysaccharidoses: the role of glycosaminoglycan-mediated inflammation. J Pediatr Rehabil Med 3(2):85-88. doi:10.3233/ PRM-2010-0120

15. Lachman R, Martin KW, Castro S, Basto MA, Adams A, Teles EL (2010) Radiologic and neuroradiologic findings in the mucopolysaccharidoses. J Pediatr Rehabil Med 3(2):109-118. doi:10.3233/PRM-2010-0115

16. Vedolin L, Schwartz IV, Komlos M, Schuch A, Azevedo AC, Vieira T, Maeda FK, Marques da Silva AM, Giugliani R (2007) Brain MRI in mucopolysaccharidosis: effect of aging and correlation with biochemical findings. Neurology 69(9):917-924. doi:10.1212/01.wnl.0000269782.80107.fe

17. Glass RB, Norton KI, Mitre SA, Kang E (2002) Pediatrics ribs: a spectrum of abnormalities. Radiographics 22(1):87-104

18. Eich GF, Babyn P, Giedion A (1992) Pediatric pelvis: radiographic appearance in various congenital disorders. Radiographics 12(3):467-484

19. Aldenhoven M, Sakkers RJ, Boelens J, de Koning TJ, Wulffraat NM (2009) Muscoskeletal manifestations of lysosomal storage disorders. Ann Rheum Dis 68(11):1659-1665. doi:10.1136/ ard.2008.095315

20. Mankin HJ, Jupiter J, Trahan CA (2011) Hand and foot abnormalities associated with genetic diseases. Hand (NY) 6(1):18-26. doi:10.1007/s11552-010-9302-8

21. White K, Kim T, Neufeld JA (2010) Clinical assessment and treatment of carpal tunnel syndrome in the mucopolysaccharidoses. J Pediatr Rehab Med 3(1):57-62. doi:10.3233/PRM-2010-0103

22. Muhlebach MS, Wooten W, Muenzer J (2011) Respiratory manifestations in mucopolysaccharidoses. Paediatr Respir Rev 12(2):133-138. doi:10.1016/j.prrv.2010.10.005

23. Berger KI, Fagondes SC, Giugliani R, Hardy KA, Lee KS, McArdle C, Scarpa M, Tobin MJ, Ward SA, Rapoport DM (2012) Respiratory and sleep disorders in mucopolysaccharidosis. J Inherit Metab Dis :. doi:10.1007/s10545-012-9555-1

24. Wold SM, Derkay CS, Darrow DH, Proud V (2010) Role of the pediatric otolaryngologist in diagnosis and management of children with mucopolysaccharidoses. Int J Pediatr Otorhinolaryngol 74(1):27-31. doi:10.1016/j.ijporl.2009.09.042

25. Trojanowska A, Drop A, Trojanowski P, Rosińska-Bogusiewicz K, Klatka J, Bobek-Billewicz B (2012) External and middle ear diseases: radiological diagnosis based on clinical signs and symptoms. Insights Imaging 3(1):33-48. doi:10.1007/s13244011-0126-Z

26. Nagano R, Takizawa S, Hayama N, Umemura S, Uesugi T, Nakagawa S, Okamoto S, Yanagimachi N, Takagi S, Tokai J (2007) Three-dimensional CT and histopathological findings of airway malacia in Hunter syndrome. Exp Clin Med 32(2):59-61

27. Ingelmo PM, Parini R, Grimaldi M, Mauri F, Romagnoli M, Tagliabue G, Somaini M, Sahillioğlu E, Frawley G (2011) Multidetector computed tomography (MDCT) for preoperative airway assessment in children with mucopolysaccharidoses. Minerva Anestesiol 77(8):774-780

28. Santamaria F, Andreucci MV, Parenti G, Polverino M, Viggiano D, Montella S, Cesaro A, Ciccarelli R, Capaldo B, Andria G (2007) Upper airway obstructive disease in mucopolysaccharidoses: polysomnography, computed tomography and nasal endoscopy findings. J Inherit Metab Dis 30(5):743-749. doi:10.1007/ s10545-007-0555-5

29. Simmons MA, Bruce IA, Penney S, Wraith E, Rothera MP (2005) Otorhinolaryngological manifestations of the mucopolysaccharidoses. Int J Pediatr Otorhinolaryngol 69(5):589-595. doi:10.1016/ j.ijporl.2005.01.017

30. Patay Z (2005) Diffusion-weighted MR imaging in leukodystrophies. Eur Radiol 15(11):2284-2303. doi:10.1007/s00330-005-2846-2

31. Manara R, Priante E, Grimaldi M, Santoro L, Polonara G, Parini R, Scarpa M, Italian MPS Neuroimaging Study Group (2012) Closed Meningo(encephalo)cele: a new feature in Hunter syndrome. AJNR Am J Neuroradiol 33(5):873-877. doi:10.3174/ajnr.A2867

32. Matheus MG, Castillo M, Smith JK, Armao D, Towle D, Muenzer J (2004) Brain MRI findings in patients with mucopolysaccharidosis types I and II and mild clinical presentation. Neuroradiology 46(8):666-672. doi:10.1007/s00234-004-1215-1

33. Manara R, Priante E, Grimaldi M, Santoro L, Astarita L, Barone R, Concolino D, Di Rocco M, Donati MA, Fecarotta S, Ficcadenti A, Fiumara A, Furlan F, Giovannini I, Lilliu F, Mardari R, Polonara G, Procopio E, Rampazzo A, Rossi A, Sanna G, Parini R, Scarpa M (2011) Brain and spine MRI features of Hunter disease: frequency, natural evolution and response to therapy. J Inherit Metab Dis 34(3):763-780. doi:10.1007/s10545-011-9317-5

34. Müller-Forell W, Schulze Frenking G, Amraoui Y, Beck M (2007) Mucopolysaccharidoses (MPS) clinical and neuroradiological aspects of the different types. Clin Neuroradiol 17:141-158. doi:10.1007/s00062-007-7017-1

35. Zafeiriou DI, Batzios SP (2013) Brain and spinal MR imaging findings in mucopolysaccharidoses: a review. AJNR Am J Neuroradiol 34(1):5-13. doi:10.3174/ajnr.A2832

36. Shimoda-Matsubayashi S, Kuru Y, Sumie H, Ito T, Hattori N, Okuma Y, Mizuno Y (1990) MRI findings in the mild type of mucopolysaccharidosis II (Hunter's syndrome). Neuroradiology 32(4):328-330

37. Parsons VJ, Hughes DG, Wraith JE (1996) Magnetic resonance imaging of the brain, neck and cervical spine in mild Hunter's syndrome (mucopolysaccharidoses type II). Clin Radiol 51:719 723. doi:10.1016/S0009-9260(96)80246-7

38. Lee C, Dineen TE, Brack M, Kirsch JE, Runge VM (1993) The mucopolysaccharidoses: characterization by cranial MR imaging. AJNR Am J Neuroradiol 14(6):1285-1292

39. Vedolin L, Schwartz IV, Komlos M, Schuch A, Puga AC, Pinto LL, Pires AP, Giugliani R (2007) Correlation of MR imaging and MR spectroscopy findings with cognitive impairment in mucopolysaccharidosis II. AJNR Am J Neuroradiol 28(6):1029 1033. doi:10.3174/ajnr.A0510

40. Gabrielli O, Polonara G, Regnicolo L, Petroni V, Scarabino T, Coppa GV, Salvolini U (2004) Correlation between cerebral MRI abnormalities and mental retardation in patients with mucopolysaccharidoses. Am J Med Genet A125A(3):224-231. doi:10.1002/ajmg.a.20515 
41. Wendy R, Smoker K, Khanna G (2008) Imaging of the craniocervical junction. Childs Nerv Syst 24:1123-1145. doi:10.1007/s00381-0080601-0

42. Davison JE, Hendriksz CJ, Sun Y, Davies NP, Gissen P, Peet AC (2010) Quantitative in vivo brain magnetic resonance spectroscopic monitoring of neurological involvement in mucopolysaccharidosis type II (Hunter syndrome). J Inherit Metab Dis: doi:10.1007/s10545-010-9197-0

43. Davison JE, Kearney S, Horton J, Foster K, Peet AC, Hendriksz CJ (2012) Intellectual and neurological functioning in Morquio syndrome (MPS IVa). J Inherit Metab Dis :. doi:10.1007/s10545011-9430-5

44. Takahashi Y, Sukegawa K, Aoki M, Ito A, Suzuki K, Sakaguchi H, Watanabe M, Isogai K, Mizuno S, Hoshi H, Kuwata K, Tomatsu S, Kato S, Ito T, Kondo N, Orii T (2001) Evaluation of accumulated mucopolysaccharides in the brain of patients with mucopolysaccharidoses by ${ }^{1} \mathrm{H}$-magnetic resonance spectroscopy before and after bone marrow transplantation. Pediatr Res 49(3):349 355. doi:10.1203/00006450-200103000-00008 